University of Rhode Island

DigitalCommons@URI

Open Access Master's Theses

1966

\title{
The Comparative Cardio-Inhibitory Effects of Certain Cyclohexanol and Cyclohexylamine Derivatives
}

David Charles Kosegarten

University of Rhode Island

Follow this and additional works at: https://digitalcommons.uri.edu/theses

\section{Recommended Citation}

Kosegarten, David Charles, "The Comparative Cardio-Inhibitory Effects of Certain Cyclohexanol and Cyclohexylamine Derivatives" (1966). Open Access Master's Theses. Paper 198.

https://digitalcommons.uri.edu/theses/198

This Thesis is brought to you for free and open access by DigitalCommons@URI. It has been accepted for inclusion in Open Access Master's Theses by an authorized administrator of DigitalCommons@URI. For more information, please contact digitalcommons-group@uri.edu. 
THE COMPARATIVE CARDIO-INHIBITORY

EFFECTS OF CERTAIN CYCLOHEXANOL AND

CYCLOHEXYLAMINE DERIVATIVES

BY

DAVID CHARLES KOSEGARTEN

A THESIS SUBMITTED IN PARTIAL FULFILLMENT OF THE REQUIREMENTS FOR THE DEGREE OF

MASTER OF SCIENCE

IN

PHARMACOLOGY

UNIVERSITY OF RHODE ISLAND

1966 


\section{ABSTRACT}

Derivatives of cyclohexanol and cyclohexylamine were pharmacologically screened for cardioplegic effects on intact anesthetized rats, and isolated guinea pig hearts. Evaluation of potency was based on the ability to depress rat carotid blood pressure, and to produce cardiac arrest in the isolated guinea pig heart.

As a group, the non-ethynyl cyclohexanol derivatives were more potent in producing a hypotensive response, than were the derivatives of cyclohexylamine. trans-2-o-Tolyl-cis-1,4-cyclohexanediol and trans-2-o-tolyl-trans-1,5-cyclohexanediol were equally effective and the most active. trans $-2-(\mathrm{p}-$ Chlorophenyl)-N, N-dimethylcyclohexyl-: amine was the least active, and the only compound to produce a pressor response.

Conversely, the cyclohexylamines were more potent cardioplegic agents. The cis and trans isomers of $2-(\mathrm{p}-$ chlorophenyl)-N, N-dimethyl cyclohexylamine were equally the most active with trans-2-o-tolylcis-1,4-cyclohexanediol the least active. The minimum effective cardioplegic dose of 1 -ethynyl-trans-2-o-tolylcyclohexanol was also the cardiotoxic dose as the heart failed to recover from arrest.

Mechanism studies on spontaneously beating isolated rat atria indicate an antagonistic effect between calcium and the negative inotropic action of these compounds. 
MASTER OF SCIENCE THESIS

OF

DAVID CHARLES KOSEGARTEN

Approved:

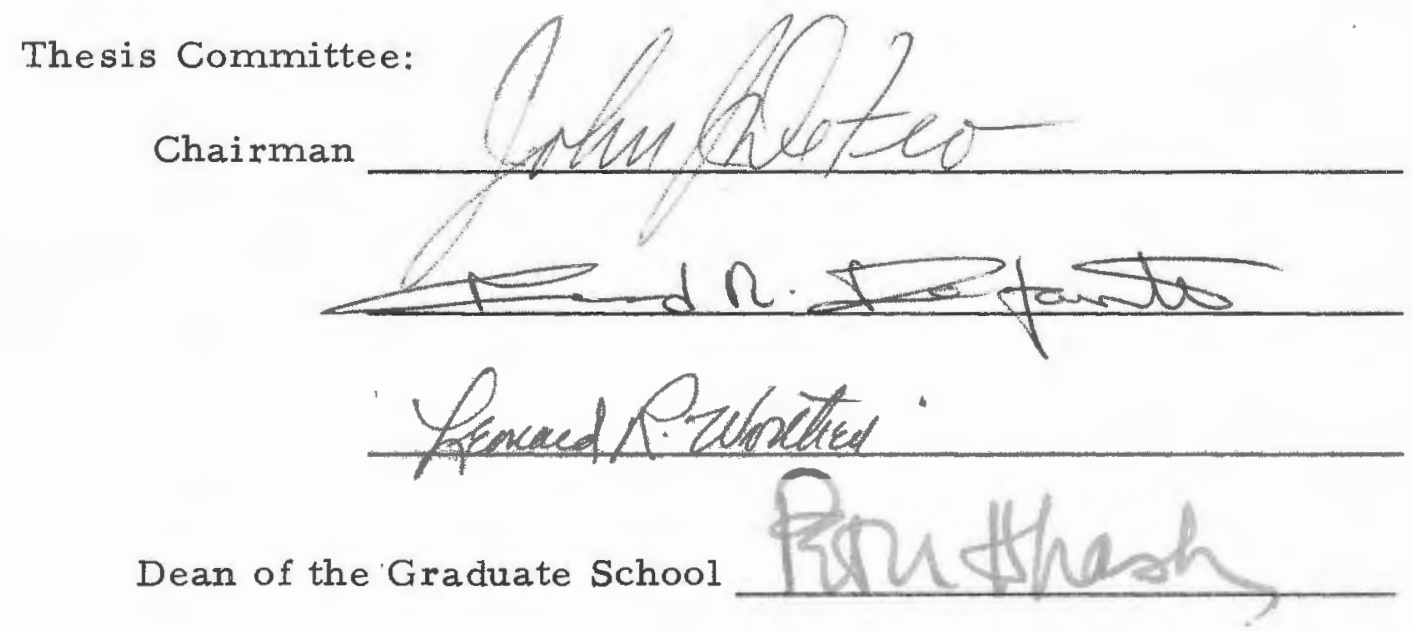

UNIVERSITY OF RHODE ISLAND

1966 
TABLE OF CONTENTS

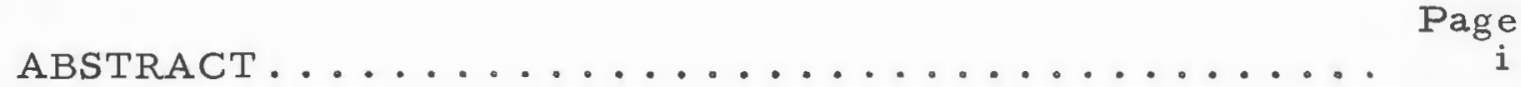

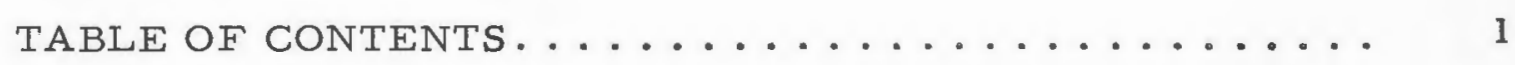

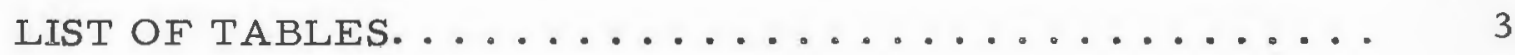

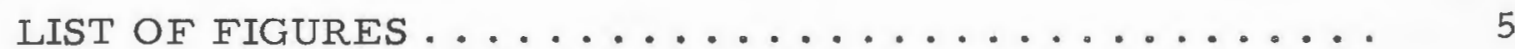

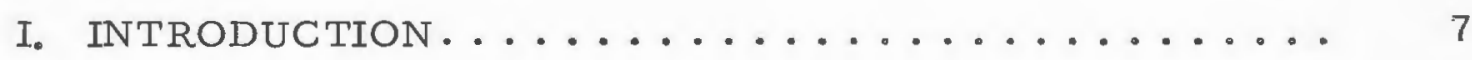

I I. REVIEW OF THE LITERATURE ............... 10

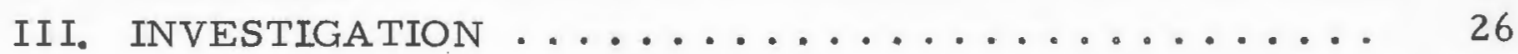

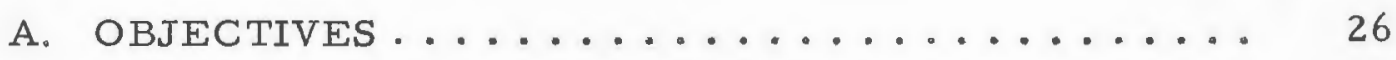

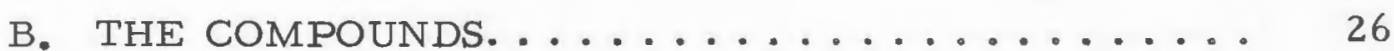

C. DETERMINATION OF COMPOUND SOLUBILITY .... 27

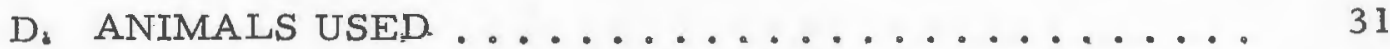

E. EXPERIMENTAL PROCEDURES AND RESULTS .... 31

1. Effects of the Non-Ethynyl Cyclohexanol derivatives and the Cyclohexylamine Hydrochloride Salts on the Blood Pressure of Rats.........

2. Effects of the Cyclohexanol Derivatives and the Cyclohexylamine Hydrochloride Salts on the Contractility of the Isolated Guinea Pig Heart ....

3. Effects of trans-2-o-Tolyl, trans-1,5-cyclohexanediol and cis-2-(p-Clo rophenyl)-N, N-dimethylcyclohexylamine Hydrochloride on the Contract- 


\section{TABLE OF CONTENTS}

ility of the Isolated Rat Atria.............. $\quad 65$

4. Effects of trans-2-(p-Chlorophenyl)-N, N-dimethylcyclohexylamine Hydrochloride ( $\mathrm{TH}-25)$ on the Blood Pressure of Both the Hexamethonium Treated and Reserpine Pretreated Rat.............

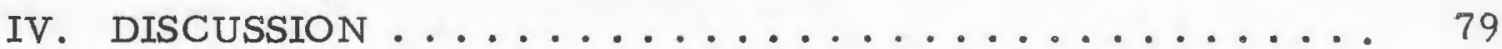

A. BLOOD PRESSURE STUDIES ................ 79

B. ISOLATED HEART STUDIES .................. 83

C. ISOLATED ATRIAL STUDIES ...................... 89

D. PRELIMINARY INVESTIGATION OF THE PRESSOR RESPONSE OF $(\mathrm{TH}-25) \ldots \ldots . \ldots . \ldots 91$

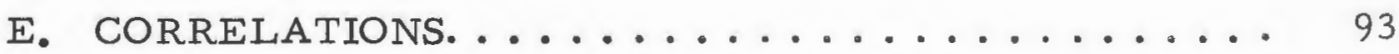

V. SUMMARY AND CONCLUSIONS ................... 95

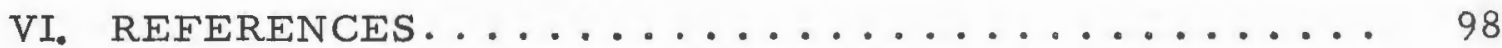

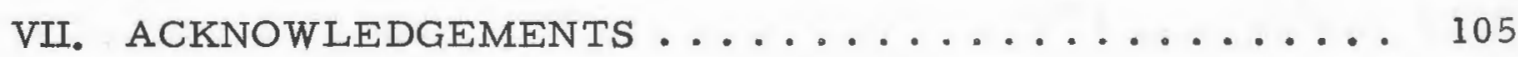




\section{LIST OF TABLES}

TABLE

PAGE

I. Physical state and water solubility of the nonethynyl cyclohexanol derivatives and of the cyclohexylamine hydrochloride salts................

II. Effects of trans-2-o-tolyl-cis-4-hydroxy-trans-5hydroxycyclohexanol ( $\mathrm{CH}-21)$ on the blood pressure

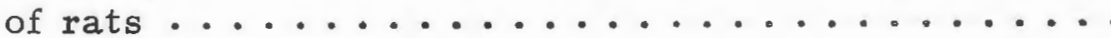

III. Effects of trans-2-o-tolyl-cis-1,4-cyclohexanediol $(\mathrm{CH}-14)$ on the blood pressure of rats........

I V.. Effects of trans-2-o-tolyl-trans-1,5-cyclohexanediol $(\mathrm{CH}-20)$ on the blood pressure of rats.......

V. Effects of trans-2-(p-chlorophenyl)-N, N-dimethylcyclohexylamine HCL (TH-25) on the blood pressure

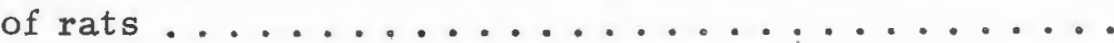

VI. Effects of trans-2-(p-chlorophenyl)-N-methylcyclohexylamine HCL $(\mathrm{TH}-26)$ on the blood pressure of

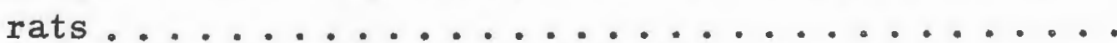

VII. Effects of cis-2-(p-chlo rophenyl)-N, N-dimethylcyclohexylamine HCL (TH-27) on the blood pressure

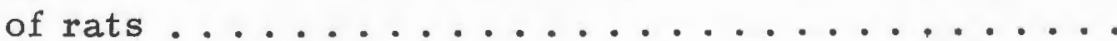

VII. A comparison of the ED 50 (hypotensive) of the nonethynyl cyclohexanol derivatives and the cyclohexylamine derivatives on the blood pressure of

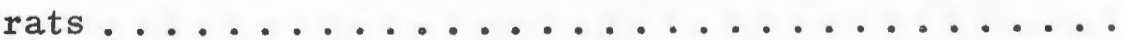

IX Effects of trans-2-o-tolyl-cis-1,4-cyclohexanediol $(\mathrm{CH}-14)$ on the isolated guinea pig heart .......

X. Effects of trans-2-o-tolyl-trans-1,5-cyclohexanediol ( $\mathrm{CH}-20)$ on the isolated guinea pig heart .....

XI. Effects of 1-ethynyl-trans-2-o-tolylcyclohexanol $(\mathrm{AH}-64)$ on the isolated guinea pig heart ....... 


\section{LIST OF TABLES}

\section{TABLE}

PAGE

XII. Effects of 1-ethynyl-cis-2-o-tolylcyclohexanol $(\mathrm{AH}-65)$ on the isolated guinea pig heart .......

XIII. Effects of trans-2-(p-chlorophenyl)-N, N-dimethylcyclohexylamine HCL (TH-25) on the isolated

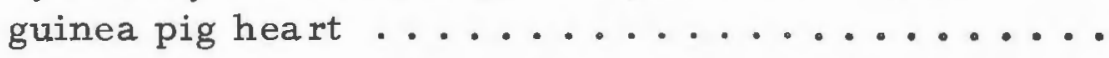

XIV. Effects of trans-2-(p-chlorophenyl)-N-methylcyclohexylamine HCL $(\mathrm{TH}-26)$ on the isolated guinea pig

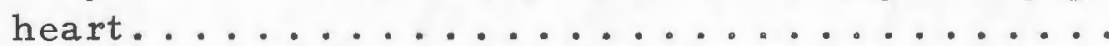

XV. Effects of cis-2-(p-chloropheny1)-N, N-dimethylcyclohexylamine HCL (TH-27) on the isolated

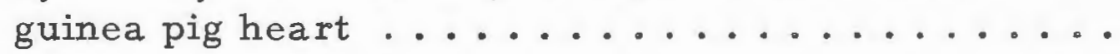

XVI. A comparison of the ED95 (cardio-inhibitory) of the cyclohexanol and cyclohexylamine derivatives on the isolated guinea pig heart ............ 


\section{LIST OF FIGURES}

FIGURE

PAGE

1. Cyclohexylamine hydrochloride derivatives ...... 28

2. Cyclohexanol derivatives ................... 29

3. Rat blood pressure response to each of the cyclohexylamine hydrochloride salts $(4.0 \mathrm{mg} . / \mathrm{Kg}$. $) ..$.

4. A comparison of the hypotensive effects produced by the cyclohexanol derivatives .............

5. A comparison of the blood pressure effects produced by the cyclohexylamine hydrochloride derivatives....

6. The cardio-toxic effect of 1-ethynyl-trans-2-otolylcyclohexanol (3.0 mg.) on the isolated guinea

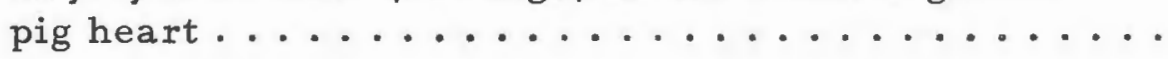

7. The effect of calcium chloride $(8.0 \mathrm{mg}$. and $16.0 \mathrm{mg}$.) on the isolated guinea pig heart following $1.0 \mathrm{mg}$. of 1 -ethynyl-cis-2-o-tolylcyclohexanol ........

8. The effect of trans-2-(p-chlorophenyl)-N, N-dimethylcyclohexylamine hydrochloride $(1.0 \mathrm{mg}$.) on the isolated guinea pig heart...............

9. The effect of trans-2-(p-chlorophenyl)-N-Methylcyclohexylamine hydrochloride $(2.0 \mathrm{mg}$.) on the

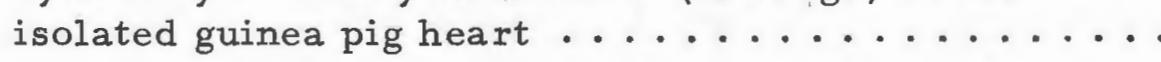

10. The effect of cis-2-(p-chlorophenyl)-N, N-dimethyl cyclohexylamine hydrochloride $(1.0 \mathrm{mg}$.) on the isolated guinea pig heart..............

11. A comparison of the cardio-inhibitory effects pro-duced by the derivatives of cyclohexanol and cyclohexylamine hydrochloride..............

12. The effects of trans-2-o-tolyl-trans-1,5-cyclohexanediol (0. $6 \mathrm{mg}$.) and calcium chloride $(4.0 \mathrm{mg}$.)

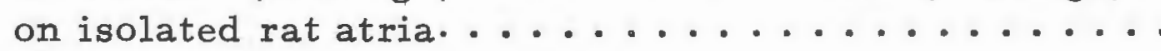




\section{LIST OF FIGURES}

FIGURE

13. The effects of cis-2-(p-chlorophenyl)-N, N-dimethylcyclohexylamine hydrochloride $(0.6 \mathrm{mg}$. and $1.2 \mathrm{mg}$.) and calcium chloride $(4.0 \mathrm{mg}$. and $8.0 \mathrm{mg}$.) on isolated rat atria................... 69

14. The effect of trans-2-(p-chlorophenyl)-N, N-dimethylcyclohexylamine hydrochloride $(4.0 \mathrm{mg} . / \mathrm{Kg}$.) on rat blood pressure, prior to hexamethonium $(20 \mathrm{mg}$. $/ \mathrm{Kg}$. ).

15. The effect of trans-2-(p-chlorophenyl)-N, N-dimethylcyclohexylamine hydrochloride $(4.0 \mathrm{mg} . / \mathrm{Kg}$.) on rat blood pressure, following hexamethonium $(20 \mathrm{mg}$. $/ \mathrm{Kg}$.). .

16. The effect of trans-2-(p-chlo rophenyl)-N, N-dimethylcyclohexylamine hydrochloride $(4.0 \mathrm{mg} . / \mathrm{Kg}$.$) on the$ blood pressure of the reserpine pretreated rat prior to dibenamine $(15 \mathrm{mg} . / \mathrm{Kg}.) \ldots \ldots \ldots \ldots$

17. The effect of trans-2-(p-chlorophenyl)-N, N- dimethylcyclohexylamine hydrochloride $(4.0 \mathrm{mg}$. $/ \mathrm{Kg}$.) on the blood pressure of the reserpine pretreated rat follow:-

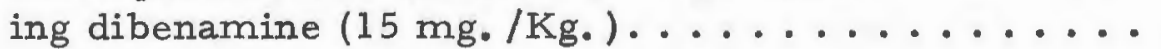




\section{INTRODUCTION}

Today, "open-heart" surgery has changed the outlook for a great many cardiac patients, particularly those having congenital defects, which would have been labeled as hopeless cases slightly more than ten years ago. The performance of the first successful "open-heart" or direct vision operation in this country, was reported by Lewis and Taufic in 1953.

In the years that followed, many valuable adjuncts to direct vision surgery have been developed. For example, the us e of plastic patches and valves to replace missing or damaged tissues in the heart; and the fully mechanical heart-lung machine as reported by Gibbon in 1954. By utilizing the heart-lung machine, the surgeon is able to interrupt the function of the heart and lungs at the expense of the machine, which does the pumping for the heart and conducts the pulmonary exchange of oxygen and carbon dioxide; an extracorporeal circulation.

Another important aid in the surgical treatment of intracardiac defects, is the still heart. Under certain conditions, where a dry, motionless and clearly visible operative field is desirable, an arrested and all-but-bloodless heart enables the surgeon to repair more accurately a particular defect.

Elective cardiac arrest has been experimentally and clinically 
produced by several methods. These consist chiefly of inducing arrest by hypothermia, myocardial anoxia, pharmacological agents, or a combination of any or all three. Since this investigation deals with the pharmacological approach to elective cardiac arrest, the review of the literature will be confined accordingly.

Other methods such as total body hypothermia, local cooling of the heart, and myocardial anoxia appear to be favored at present over known methods of chemical cardioplegia. One reason for this, is the apparent unlikeliness that the "ideal" cardioplegic agent or combination of agents has been found. According to Stephenson (1964), such an agent should have a prompt and complete effect of proper duration, be free from toxicity, and characterized by a completely reliable recovery period.

In 1959 Huitric et al., reported that 2-(o-tolyl)-cyclohexanol was capable of producing reversible cardiac arrest, without affecting myocardial electrical properties. This finding stimulated the preparation of a number of substituted cyclohexanol derivatives by Huitric.

Previous pharmacologic evaluation studies by Smookler and DeFeo (1962) and Smith (1963) showed the degree of cardio-inhibitory activity to be related to the functional groups and stereochemistry of the se compounds.

In continuation, therefore, the present investigation was carried 
out on additional compounds prepared by Huitric, in an effort to determine their possible cardio-inhibitory activity, and its relationship to molecular structure. 


\section{REVIEW OF THE LITERATURE}

Perhaps the first to draw attention to the effect of the various cations on the heart beat, was Ringer (1882). While performing heart perfusion experiments, he noted that the addition of small quantities of potassium chloride to the perfusing fluid resulted in diastolic ventricular arrest. Again in 1883, Ringer described the antagonism existing in heart muscle between calcium and potassium salts; an excess of calcium resulted in "fusion of the beats" or systolic arrest, whereas increased amounts of potassium weakened the beat and diastolic arrest ensued.

In an effort to restore normal rhythm to the fibrillating ventricles of the dog, Hooker (1929) showed that potassium chloride produced cardiac arrest when injected under pressure into the carotid artery toward the heart. Normal rhythm was then restored upon the injection of calcium by the same route.

Thus was laid the real foundation for the production of elective cardiac arrest by chemical means. To date, only the potassium salts and acetylcholine have achieved any status as cardioplegic agents.

Senning (1952) was able to stop cardiac contractions for a brief period using methacholine, acetylcholine, and potassium chloride. However, he was unsuccessful in producing prolonged asystole, as 
coronary perfusion was maintained which quickly washed out the cardioplegic ions.

Lam and his associates (1955) used 5 per cent potassium chloride injected into the dog's left ventricle and produced cardiac arrest for periods of ten to thirty minutes. During the recovery period a high incidence of ventricular fibrillation occurred and nine of ten arrested hearts were restored to normal rhythm by countershock.

Melrose et al. (1955), working with potassium citrate, produced cardiac arrest in isolated rabbit, guinea pig, and kitten hearts. Moreover, he instituted the "Melrose" technique for producing asystole. An injection of a mixture of potassium citrate and aspirated whole blood into the base of the cross-clamped aorta, resulted in diastolic arrest of the heart. Arrest was maintained as long as an adequate level of potassium citrate remained in the coronary arteries, and normal rhythm was restored when simple perfusion of the coronary circulation reduced the concentration of potassium citrate.

Baker and Dreyer (1956) found it possible to stop the same isolated heart ten times for at least fifteen minute periods, each with coronary flow inter rupted. In control hearts, without potassium citrate the hearts recovered poorly. They reported that no antagonist to potassium citrate was needed to restore the beat, just normal 
perfusion. Moreover, the proportions of potassium and citrate in potassium citrate itself were the best for causing complete cardiac arrest without persistent ventricular fibrillation.

Bentall and Melrose (1957) in studying the production of lactic acid in isolated perfused hearts after varying periods of arrest, reported that potassium citrate did offer some protection against its anae robic build up.

Using the technique of Melrose, Kolff et al. (1956) reported ventricular fibrillation in only one of ten dogs with cardiac arrest up to twenty-three minutes, and Effler et al. (1956) successfully treated two of three cases of congenital heart disease with the heart resuming normal sinus rhythm in all three cases. However, following thirtyseven open-heart operations, Kolff et al. (1957) reported that with potassium citrate, cardiac arrest as long as forty minutes had been attained. Ventricular fibrillation had occurred; but was restored to normal sinus rhythm in seven instances. It was suggested that higher perfusion rates might increase the speed with which the heart beat recovers after potassium citrate, and thus might reduce the incidence of temporary arrhythmias. Effler et al. (1957) also observed ventricular fibrillation frequently in reporting on the clinical feasibility of the "Melrose" technique as an aid to open-heart surgery. Meanwhile, acetylcholine began to be used by other investigators 
as a cardioplegic agent. Previously, Bjork (1948) had been unsuccessful in stopping the heart with acetylcholine in at least one experiment on the dog. However, acetylcholine was shown by Sergeant et al. (1956) to be a safe and effective cardioplegic agent for both the hypothermic and normothermic dog heart. They reported similar success in a series of eight human open-heart operations. Moulder et al. (1956) also reported success in the use of acetylcholine to inhibit cardiac contractions in dog and humans under hypothermia.

Lam et al. (1957, 1957a, 1958), using acetylcholine as the cardioplegic agent, reported on its clinical safety and low incidence of ventricular fibrillation during recovery. It was noted however, that during arrest with acetylcholine the heart might beat if the ventricle wall was stimulated mechanically by forceps or needles.

Despite the success reported with the use of acetylcholine, interest remained in the "Melrose" technique of elective cardiac arrest with potassium citrate. Kaplan et al. (1958) called attention to a high incidence of ventricular fibrillation following the use of the "Melrose" technique in dogs. In sustaining a 50 per cent mortality rate with this method the authors suggested that the ideal drug for cardioplegia should have a known and predictable reversible effect. Helmsworth et al. (1958) reported that the high incidence of refractory ventricular fibrillation following potassium citrate arrest 
might be due to the high concentration of potassium in blood taken from the left atrium. This was in contrast to only a slight rise in atrial potassium concentration following acetylcholine arrest.

In an effort to overcome the ventricular fibrillation associated with the "Melrose" technique of cardiac arrest, Milnes et al. (1958) combined potassium citrate with magnesium sulfate in arresting the dog heart. The combination appeared to have a synergistic effect. Consistent survival, with no fibrillation was reported in animals undergoing cardiac arrest for thirty-five minutes or less.

In a similar approach Sealy et al. (1958) and Merritt et al. (1958) used a combination of potassium citrate, magnesium sulfate, and neostigmine. The protective action of neostigmine depends in part on the production of acetylcholine which in turn depends on the concentration of ATP. Baer et al. (1956) had shown that the protective action of neostigmine alone against ventricular fibrillation was less when the coronary ostia were occluded, presumably because of the low concentration of ATP resulting from anaerobic glycolysis.

It was at this time that several investigators began measuring myocardial depression associated with elective cardiac arrest. Weirich et al. (1959) observed that the ability of the ventricles to perform work was better following acetylcholine induced asystole, 
than with potassium citrate. Willman et al. $(1959,1959$ a) reported that thirty minutes of cardiac arrest induced by potassium citrate, acetylcholine, and a mixture of potassium citrate, magnesium sulfate, and neostigmine severely impaired the ability of the canine heart to do work as determined by the profound decrease in cardiac output and cardiac stroke work. The authors suggested the use of cardiotonic agents to lower the demands on cardiac output and increase work capacity during the post-operative period.

Accordingly, Cooper et al. (1959) studied left ventricular function in dogs. The cardiotonic agent mephentermine was used postoperatively where there was evidence of severe myocardial depression following thirty minutes of elective cardiac arrest with potassium citrate. It was indicated that mephentermine might be useful in the post-operative management of subjects who had undergone extended periods of cardiac arrest. Moreover, in similar studies by the same authors $(1959 \mathrm{a}, 1960)$ it was shown that hypothermia and also predigitalization offered partial protection to the canine myocardium subjected to thirty minutes of arrest with potassium citrate.

A method for prolonging induced cardioplegia was proposed by Headrick et al. (1959). Initial cardiac arrest was obtained by injecting a 2.5 per cent potassium citrate in saline into the base of the canine aorta. The coronaries were then cannulated with self 
containing Manlove cannulae and continuously perfused with oxygenated blood containing the cardioplegic agent potassium citrate. Perfusate was drained from a right atrial cannula and returned to a pumpoxygenator system. After three hours of cardiac arrest produced in this manner, all of the hearts could maintain a normal rhythm after extracorporeal circulation was discontinued.

Kaplan and Fisher (1959) studied the metabolism and fate of potassium used as a cardioplegic agent. Using $\mathrm{K}^{42}$-potassium citrate in both normothermic and hypothermic dogs, reversibility of cardioplegia did not seem to be related to the amount of potassium injected or to its concentration in the myocardium. The washing out of potas sium and the resumption of normal rhythm were not synonymous, and the mortality in normothermic dogs was less than that of hypothermic animals. With predigitalization the mortality of the latter group was significantly reduced. Most of the radioactive potassium was found in the middle third of the interventricular septum, perhaps explaining the relatively high incidence of ventricular fibrillation following its use. The authors thus suggested that the safety of a future cardioplegic agent might well depend upon there being a specific anti-cardioplegic drug. Such a compound should be equally effective in re-establishing a normal physiologic state.

In an effort to combine local hypothermia with chemical 
cardioplegia, Kenyon et al. (1959) administered potassium citrate and acetylcholine with the infusate temperature at $4^{\circ} \mathrm{C}$ or $5^{\circ} \mathrm{C}$. Cardiac arrest occured in only 40 per cent of the animals treated with acetylcholine compared to 100 per cent of those injected with potassium citrate. They concluded that the only reliable means of producing complete cardiac arrest was with the combination of potassium citrate and cold infusate.

Biopsies taken from human hearts before, during, and at the end of potassium citrate arrest and arrest produced by cooling coronary blood to about $10^{\circ} \mathrm{C}$, were analyzed by Gott et al. (1959) for various energy substances. The levels of ATP, phosphocreatine and glycogen fell much more rapidly following potassium citrate arrest, than following selective hypothermic arrest. Also, tissue lactic acid rose more rapidly with potassium citrate arrest. It was concluded that arrest brought about by selective hypothermia was far superior to arrest by potassium citrate for the maintenance of myocardial energy resources.

Dodrill and Takagi (1960) showed that the addition of ATP to potassium citrate arrest mixture allowed a much longer time of anoxic metabolism and enabled the heart to utilize oxygen better in the post arrest period.

The studies of Redo (1959) and Redo and Porter (1959), showed oxygen to be a more important factor upon the reversibility of 
myocardial function after arrest, than was glucose. Furthermore, Redo believed arrest produced by the accumulation of endogenous potassium was reversible, while that produced by lack of oxygen, energy substrate (glucose) or both was not reversible.

In an effort to lower oxygen consumption of the arrested heart, without having to use hypothermia, Clark et al. (1959) perfused the heart with hypocalcemic arterialized blood. The heart so perfused in situ with cardiopulmonary by-pass, recovered from forty-five minutes of arrest, with no gross evidence of damage.

Myocardial necrosis was reported by McFarland et al. (1960) in 79 per cent of patients who had undergone potassium citrate cardiac arrest and who had died at various intervals following open heart surgery. The lesion was not observed in the hearts of patients who underwent similar procedures without arrest or with anoxic arrest. The authors stated that these findings led to the abandonment of the "Melrose" technique at the National Heart Institute.

Yashar et al. (1960) felt that none of the cardioplegic agents they used in dog experiments, appeared safe for routine clinical use. Recovery from arrest by potassium citrate, acetylcholine, sodium citrate, sodium phytate, methacholine, and potas sium chloride was accompanied by a high incidence of ventricular fibrillation. Moreover, no relationship was observed between the dose of a particular 
agent, the duration of cardiac arrest or the rate of recovery.

In evaluating the effect of potassium and magnesium ions used to arrest the isolated perfused rabbit heart, Mouritzen and Albrechtsen (1960), concluded that both ions were capable of inducing controlled arrest; but that the toxic effect of magnesium was higher than that of potassium. After exposure to magnesium, arrhythmias were more frequent and the reduction in amplitude of contraction was greater than after similar exposure to potassium. Further work by these investigators (1961) re-emphasized the injurious effect of the magnesium ion and to a lesser degree the potassium ion, on the isolated heart. Reduction of the temperature from $37^{\circ} \mathrm{C}$ to $29^{\circ} \mathrm{C}$ protected the isolated heart to a certain extent, from the injurious effects caused by the ions, as well as those caused by a deficiency in oxygen. It was noted that the withdrawal of oxygen administration for sixty minutes during total cardiac arrest appeared to damage the heart more than continued administration of potassium ions for an equivalent time. Moreover; at $37^{\circ} \mathrm{C}$, the heart did not recover from sixty minutes of potassium citrate arrest, while at $29^{\circ} \mathrm{C}$ recovery was accompanied by a considerable decrease in the amplitude of contraction.

Kusinoki et al. (1960) studied the ventricular performance of dogs having undergone acetylcholine, potassium citrate, and hypoxic cardiac arrest in the normothermic and hypothermic states. Cardiac 
arrest for fifteen minutes by any method resulted in depression of myocardial function of 50 to 70 per cent of control function. At normal body temperature, recovery appeared to be most rapid after potassium citrate and most delayed after hypoxia. Hypothermia partially protected the hypoxic heart and in comparison with the other methods studied, cardioplegia by this technique resulted in the least depression and best recovery of myocardial function. Bjork and Fors (1961) preferred using deep hypothermia to potassium citrate, acetylcholine or hypoxia as a method of producing cardiac arrest. Oxygen demands were diminished and fewer pathologic changes in the myocardium were observed during this type of arrest.

Parker et al. (1961), McKain et al. (1961), and Bhonslay et al. (1961) all reported difficulty in obtaining satisfactory cardiac arrest with acetylcholine. Each group observed ventricular fibrillation following its use. The latter investigators in comparing acetylcholine, carbachol, and potassium citrate cardioplegia, concluded potassium citrate to be the only agent that consistently produced almost immediate cardiac arrest.

Miller et al. (1961) compared the effect of cardiac arrest by potassium citrate, anoxia, and a combination of anoxia with local hypothermia on myocardial structure and function. The changes in heart function following potassium citrate arrest, although severe, were 
less than those observed in other groups. Glycogen was preserved better in hearts arrested by potassium citrate than in those arrested by anoxia with or without local hypothermia. There was however, extensive myocardial necrosis following one hour of potassium citrate arrest. Gross and microscopic areas of necrosis were again observed by Miller et al. (1964) in dog hearts twenty-four to forty-eight hours following recovery from potassium citrate arrest. In contrast, no morphologic changes were noted immediately after cardiac arrest by profound hypothermia with or without coronary perfusion. Irrevers ible degenerative lesions were demonstrated however, in the heart cells of 50 per cent of the surviving animals regardless of the type of arrest or its duration.

Isolated perfused guinea pig hearts were subjected to prolonged periods of cardioplegia by Redo (1962). Mechanical recovery of 83 to 100 per cent followed arrest up to periods of sixty minutes achieved by the use of potassium citrate plus magnesium sulfate, or hypothermia. Anoxic arrest lead to the poorest return of cardiac action as compared with the other methods used. Fibrillation during recovery, occurred in all instances after prolonged periods of cardioplegia except when arrest was achieved by hypothermia. A direct relationship existed between the duration of arrest and the length of time the heart took to recover. Similarly, mechanical recovery was poorer following 
prolonged cardioplegia.

Kaplan and Fisher (1962) proposed that the incorporation of potassium into the myocardium might be related to the carrier used to transport the ion. The potassium vehicles used were whole blood, 50 per cent glucose in water, 10 per cent glucose in saline, and isotonic saline. Survival was highest and fibrillation was lowest when 10 per cent glucose in saline was used; and although whole blood is widely used as a vehicle, results with this carrier were considered unsatisfactory. A more satisfactory recovery of the heart was believed to accompany the maintenance of myocardial cell reactivity by proper nutrition (glucose) and the presence of the sodium ion.

In evaluating potassium citrate, anoxic and hypothermic cardioplegia in patients treated with open heart surgery, Brewer et al. (1962) found hypothermic arrest to be superior. The mortality figure was highest following the use of potassium citrate, and lowest after hypothermic arrest. Microscopic sections of myocardium removed from patients not surviving, showed degeneration to be more severe after potassium citrate or anoxic arrest.

Burdette and Al-Shamma (1962) reported a decrease in myocardial $\mathrm{ATP}$ and a concommitant increase in $\mathrm{ADP}$ and $\mathrm{AMP}$ during normothermic hypoxic or potassium citrate arrest accompanied by cardiopulmonary by-pass. These metabolic changes during arrest were not 
prevented by a temperature of $27^{\circ} \mathrm{C}$, even though recovery appea red to be facilitated by hypothermia.

Previously, Gott et al. (1959) observed that the canine heart arrested with potassium citrate or by anoxia developed complete rigor mortis when the level of ATP fell to the range of 15 per cent of its initial value. Gott et al. (1962) suggested that by determining the "Time of Rigor" with different methods of cardiac arrest, an investigato $\mathrm{r}$ could obtain an approximation of the myocardial protection associated with a particular arresting technique. In measuring rigor with a special intramuscular pressure-sensor device developed by the authors, a correlation was observed between the time of complete rigor and the level of myocardial ATP. Both the normothermic and the moderately hypothermic heart arrested by potassium citrate or anoxia showed good correlation between the time of complete rigor and the myocardial ATP level.

More recently however, with respect to adenine nucleotide changes, Berne et al. (1964) were unable to show any significant difference between the potassium citrate arrested heart and the heart arrested by selective hypothermia. These findings are in contrast to those previously reported by Gott et al. (1959).

The amount of conflicting data that exists regarding the evaluation of cardioplegic agents appears to be related to the variety in the 
methods of comparison used. These have ranged from over-all survival results to tissue acidosis and oxygen consumption determinations; from histologic changes to mere recovery and contractility of the heart.

Recent literature pertaining to cardiac arrest and its use as an adjunct in open heart surgery indicates that hypothermia is presently favored over all other methods used to arrest the heart. Nevertheless, the search continues for the "ideal" cardioplegic agent possessing the aforenamed qualities and a uniform dose-response relationship.

Nelson and his associates (1958) in discussing the progress made in evaluating possible cardioplegic agents, reported that although recovery was unsuccessful, 2-(o-methylphenyl) cyclohexanol was capable of producing cardiac arrest in the dog. Huitric et al. (1959) noted that in isolated cat hearts, this compound produced reversible mechanical arrest. The complete absence of arterial pressure observed in the intact dog, following its injection was presumed by the authors to be due in part to depressed ventricular contraction.

These findings prompted Huitric to prepare a number of substituted cyclohexanol and cyclohexane derivatives. The specificity of functional groups, and structure-activity relationships associated with compounds producing reversible cardiac arrest served as guide-lines for further synthetic development. 
Previous studies showed that certain of the compounds possess potential as cardioplegic agents. Cyclohexanol and its 2 -aryl derivatives were investigated by Smookler and DeFeo (1962). All of the compounds were capable of producing an immediate drop in rat blood pressure, while the trans isomers of the (o-tolyl) and (o-chlorophenyl) compounds were the most effective in producing cardio-inhibitory effects on the isolated guinea pig heart. In preliminary mechanism studies, trans-2-o-tolylcyclohexanol antagonized the effect of the calcium ion on isolated rabbit atria. In unpublished experiments employing extracorporeal circulation, Smookler (1961) noted that although ventricular fibrillation and incompetent myocardial contractions were the major problems following arrest of the dog heart, recovery was faster and more consistent with trans-2-o-tolylcyclohexanol than with trans-2-o-chlo rophenylcyclohexanol.

Derivatives of cyclohexylamine and cyclohexane were evaluated similarly. Unpublished work of Smith (1963) showed trans-2-otolylcyclohexylamine to be the most active in its series. 2-o-tolylcyclohexen-2-one was the most active of the miscellaneous cyclohexane derivatives tested.

The present investigation of additional cyclohexanol and cyclohexylamine derivatives prepared by Huitric was carried out in an effort to further correlate molecular structure with cardio-inhibitory activity. 


\section{INVESTIGATION}

\section{A. OBJECTIVES}

Recent reports found in the literature indicate that certain substituted cyclohexanes are capable of inhibiting the cardiovascular system. Indeed, other investigators have shown that cyclohexanol and its 2-aryl derivatives, produced varying degrees of cardiac inhibition. Moreover, similar unpublished results were obtained with substituted cyclohexylamines, and miscellaneous cyclohexane derivatives.

This investigation was therefore, undertaken to determine the possible cardio-inhibitory effects of additional cyclohexanol and cyclohexylamine derivatives.

The objectives of the investigation were as follows:

1. To screen pharmacologically a series of synthetic chemical compounds for cardioplegic and hypotensive characteristics.

2. To relate the activity to the structured arrangement of the compounds screened.

3. To attempt to determine the mechanism through which these compounds act.

B. THE COMPOUNDS

The cyclohexanol and cyclohexylamine derivatives used were synthesized by Dr. Alain C. Huitric of the Department of 
Pharmaceutical Chemistry, University of Washington, College of Pharmacy, Seattle, Washington. The cyclohexylamine hydrochloride salts (Fig. 1) were freely soluble in water. The ethynyl derivatives of cyclohexanol (Fig. 2) were practically water insoluble while the remaining cyclohexanol derivatives (Fig. 2) were slightly water soluble. Accordingly, the ethynyl derivatives were dissolved in 50 per cent polyethylene glycol (PEG) 400, and aqueous solutions of the remaining cyclohexanol derivatives, as well as the cyclohexylamine hydrochloride salts were used throughout the investigation.

\section{DETERMINATION OF COMPOUND SOLUBILITY}

The water solubilities of the non-ethynyl derivatives of cyclohexanol and the cyclohexylamine hydrochloride salts were determined at room temperature $\left(22^{\circ} \mathrm{C}\right)$ according to the following procedure:

10-30 mg portions of the compound were placed in vials. All weight determinations were carried out on the Mettler ${ }^{1}$ analytical balance. The solvent volume was determined by adding deionized water dropwise from a $0.25 \mathrm{ml}$ tuberculin syringe. After each addition, the vial was thoroughly agitated on the Vortex ${ }^{2}$ mixer for one minute. The vial was then held to a bright lamp, and solution was

1. Mettler Instrument Corp. Hightstown, N. J.

2. Scientific Industries, Inc. Springfield, Mass. 


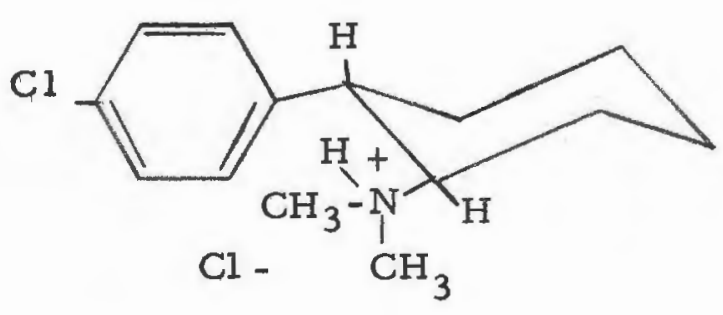

trans-2-(p-Chlorophenyl)$\mathrm{N}, \mathrm{N}$-dimethylcyclohexylamine Hydrochloride

( $\mathrm{TH}-25)$

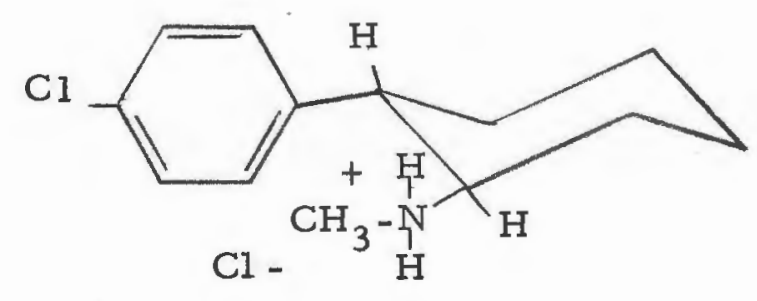

trans-2-(p-Chlorophenyl)$\mathrm{N}$-methylcyclohexylamine Hydrochloride

( $\mathrm{TH}-26)$

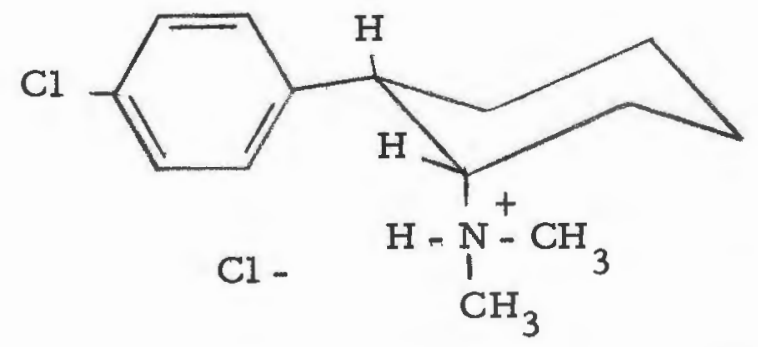

cis-2-(p-Chlorophenyl)N, N-dimethylcyclohexylamine Hydrochloride

(TH-27) 


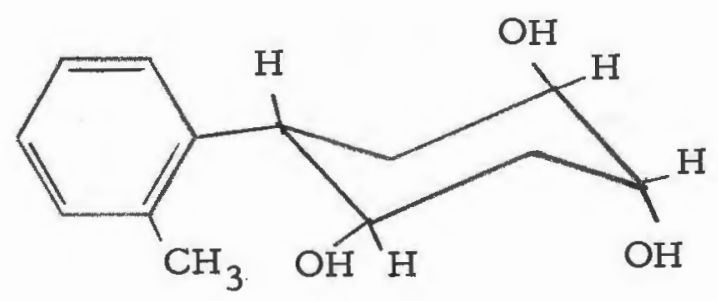

trans-2-o-Tolyl-cis-4hydroxy-trans-5-hydroxycyclohexanol (CH-2l)

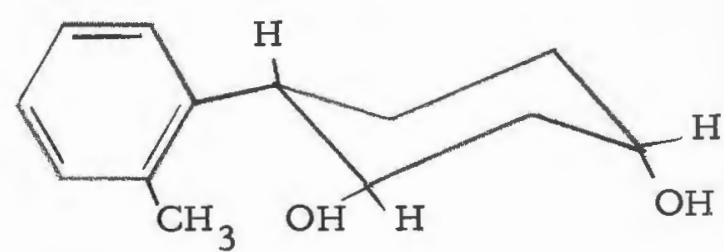

trans-2-o-Tolyl-trans1,5-cyclohexanediol ( $\mathrm{CH}-20)$

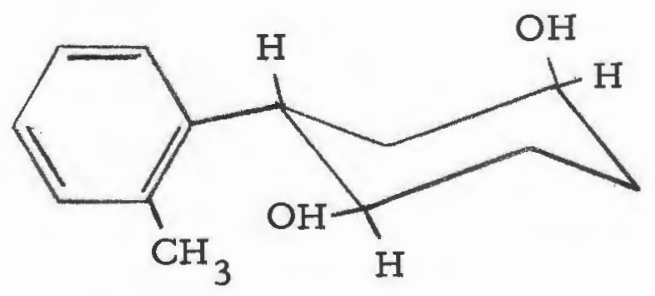

trans-2-o-Tolyl-cis-1, 4, cyclohexanediol $(\overline{\mathrm{CH}}-14)$

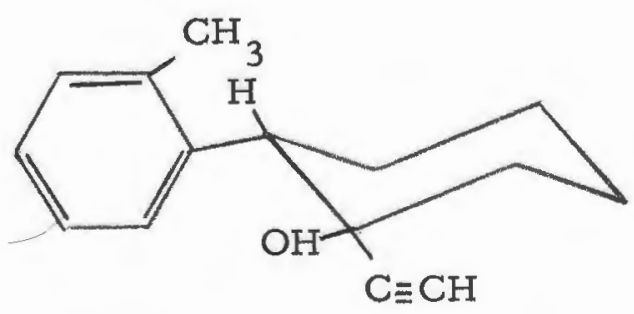

1 - Ethynyl-trans-2-o-tolylcyclohexanol (AH $-6 \overline{4})$

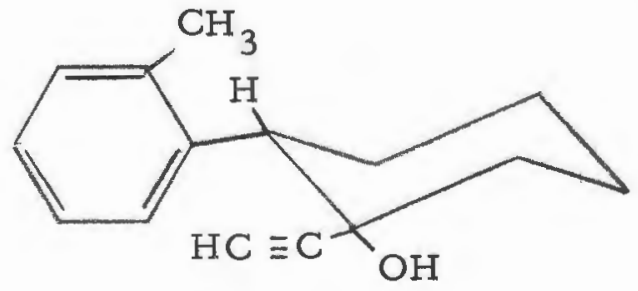

1 -Ethynyl-cis-2-o-tolylcyclohexanol (AH-65) 
Table I Physical state and water solubility of the non-ethynyl cyclohexanol derivatives and of the cyclohexylamine hydrochloride salts.

\begin{tabular}{|c|c|c|}
\hline COMPOUND & PHYSICAL STATE & $\begin{array}{l}\text { WATER } \\
\text { SOLUBILIT Y } \\
\text { at } 22^{\circ} \mathrm{C}\end{array}$ \\
\hline $\begin{array}{l}\text { trans-2-o-tolyl-cis-4- } \\
\text { hydroxy-trans }-5-\text { hydroxy- } \\
\text { cyclohexanol (CH-21) }\end{array}$ & solid & 0.58 \\
\hline$\frac{\text { trans-2-o-tolyl-cis }-1,4-}{\text { cyclohexanediol }}(\mathrm{CH}-14)$ & solid & 0.39 \\
\hline 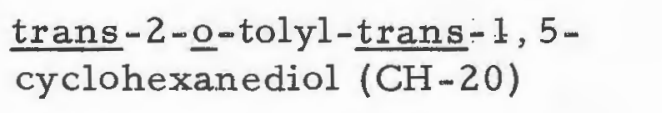 & solid & 0.95 \\
\hline $\begin{array}{l}\operatorname{trans}-2-(p-c h l o r o p h e n y l)- \\
N, N-d i m e t h y l c y c l o h e x y l- \\
\text { amine HCL (TH-25) }\end{array}$ & solid & 21.44 \\
\hline $\begin{array}{l}\text { trans }-2-(p-c h l o r o p h e n y l)- \\
\text { N-methylcyclohexylamine } \\
\text { HCL (TH }-26)\end{array}$ & solid & 29.43 \\
\hline $\begin{array}{l}\text { cis-2-(p-chlorophenyl)-N, N- } \\
\text { dimethylcyclohexylamine HCL } \\
\text { (TH-27) }\end{array}$ & solid & 35.50 \\
\hline
\end{tabular}

a parts solute/100 parts solvent 
determined to be affected or not. The whole procedure was repeated three times for each compound and the average of the determinations reported as the solubility.

The water solubilities of the ethynyl derivatives of cyclohexanol were not determined as they were dissolved in a 50 per cent mixture of polyethylene glycol (PEG) 400 and deionized water prior to testing. D. ANIMALS USED

Rats-Male albino rats of the Sprague-Dawley strain $^{1}$ were employed for all blood pressure and atrial experiments.

Guinea pigs-Guinea pigs of either sex and of a heterogeneous group were used for all isolated heart experiments. E. EXPERIMENTAL PROCEDURES AND RESULTS

The investigation was divided into four sections:

1. The effects of the cyclohexylamine hydrochloride salts and the non-ethynyl derivatives of cyclohexanol on the blood pressure of rats.

2. The inotropic effects of all compounds on the isolated guinea pig heart.

3. The inotropic and chronotropic effects of trans-2-o-tolyltrans-1,5-cyclohexanediol $(\mathrm{CH}-20)$ and cis-2-(p-chloro-

1. Charles River Breeding Farms, North Wilmington, Mass. 
phenyl)-N, N-dimethylcyclohexylamine hydrochloride (TH-27) on isolated rat atria.

4. The effects of trans-2-(p-chlorophenyl)-N, N-dimethylcyclohexylamine hydrochloride (TH-25) on the blood pressure of both the hexamethonium treated and reserpine pretreated rat. 
1. Effects of the Non-Ethynyl Cyclohexanol Derivatives and the Cyclohexylamine Hydrochloride Salts on the Blood Pressure of Rats.

\section{a.) Experimental Procedures}

The effects of the compounds on the blood pressure of male albino rats (260g. , average weight) were recorded manometrically by direct cannulation of the right carotid artery. A fluid bridge of normal saline connected the cannula to a mercury manometer, and the blood pressure responses were recorded on a slowly moving smoked kymograph.

Rats were anesthetized with $1.2 \mathrm{~g} . / \mathrm{kg}$ 。 of a freshly prepared 25 per cent urethane solution administered intraperitoneally. Injections of the test compounds were made intravenously via a needle permanently secured in the left femoral vein. To inhibit clotting, an intravenous injection of $0.01 \mathrm{ml}$. of a 1:5000 solution of heparin sodium was given to each rat prior to cannulation. A similar concentration of heparin sodium was also injected into the cannula at this time.

A minimum of twenty minutes was allowed to elapse prior to drug administration to enable the blood pressure to stabilize. Only one drug was injected for each experiment, and not more than six injections were made during one experiment. Following each injection, a twenty minute period was allotted to permit the return of the blood pressure to a normal level. At the conclusion of each experiment a urine sample was withdrawn from the bladder and observed for hematuria. 
Dosage was adjusted according to the results obtained, in order to determine the dose of a particular compound that would produce a drop in blood pressure of approximately 50 per cent. Dose and response were subjected to linear regression computations carried out by the IBM 1410 computer. The results were plotted and the dose producing a 50 per cent drop in blood pressure calculated.

The indices of activity used to compare the different compounds were as follows:

(1) The per cent drop in blood pressure produced by the various compounds.

(2) The duration of the hypotensive effect, i. e. time elapsed until the blood pressure returned to 95 per cent of the normal level.

(3) The dose of the various compounds needed to produce a 50 per cent drop in blood pressure; i. e. ED 50 (hypotensive).

\section{b. ) Results}

The results include the following:

(1) Effects of the non-ethynyl cyclohexanol derivatives and the cyclohexylamine hydrochloride salts on the blood pressure of rats (Tables II to VII).

(2) A comparison of the non-ethynyl derivatives of cyclohexanol and the cyclohexylamine hydrochloride salts on the blood pressure of rats. (Table VIII; Figs. 4 and 5). 
Table II Effects of trans-2-o-tolyl-cis-4-hydroxy-trans-5-hydroxycyclohexanol $(\mathrm{CH}-21)$ on the blood pressure of rats.

\begin{tabular}{|c|c|c|c|}
\hline $\begin{array}{c}\text { DOSE } \\
(\mathrm{mg} / \mathrm{kg})\end{array}$ & $\begin{array}{c}\text { NUMBER OF } \\
\text { TRIALS }\end{array}$ & $\begin{array}{l}\text { MEAN \% DROP } \\
\text { IN BLOOD } \\
\text { PRESSURE } \\
\pm \text { S. D. }\end{array}$ & $\begin{array}{l}\text { DURATION OF } \\
\text { DROP } \\
\text { (Mean and Range) } \\
\text { (Sec.) }\end{array}$ \\
\hline 1.0 & 2 & $22 \pm 5$ & $185(150-220)$ \\
\hline 2.0 & 2 & $33 \pm 5$ & $195(170-220)$ \\
\hline 3.0 & 3 & $32 \pm 2$ & $247(140-310)$ \\
\hline 4.5 & 1 & 46 & 400 \\
\hline 6.0 & 3 & $29 \pm 5$ & $73(50-110)$ \\
\hline 8.0 & 2 & $39 \pm 7$ & $375(280-470)$ \\
\hline 10.0 & 2 & $73 \stackrel{t}{-11}$ & $230(190-270)$ \\
\hline $12 . .0$ & 3 & $80 \pm 5$ & $203(160-250)$ \\
\hline
\end{tabular}


Table III Effects of trans-2-o-tolyl-cis-1,4-cyclohexanediol (CH-14) on the blood pressure of rats.

\begin{tabular}{cccc}
$\begin{array}{c}\text { DOSE } \\
(\mathrm{mg} / \mathrm{kg})\end{array}$ & $\begin{array}{c}\text { NUMBER OF } \\
\text { TRIALS }\end{array}$ & $\begin{array}{c}\text { MEAN \% DROP } \\
\text { IN BLOOD } \\
\text { PRESSURE } \\
\pm \text { S. D. }\end{array}$ & $\begin{array}{c}\text { DURATION OF } \\
\text { DROP } \\
\text { (Mean and Range) } \\
\text { (Sec.) }\end{array}$ \\
\hline 2.0 & 3 & $35 \pm 4$ & $207(90-310)$ \\
6.0 & 2 & $52 \pm 1$ & $280(230-330)$ \\
8.0 & 3 & $41 \pm 5$ & $200(120-300)$ \\
\hline
\end{tabular}


Table IV Effects of trans-2-o-tolyl-trans-1,5-cyclohexanediol (CH-20) on the blood pressure of rats.

\begin{tabular}{cccc}
\hline $\begin{array}{c}\text { DOSE } \\
(\mathrm{mg} / \mathrm{kg})\end{array}$ & $\begin{array}{c}\text { NUMBER OF } \\
\text { TRIALS }\end{array}$ & $\begin{array}{c}\text { MEAN \%.DROP } \\
\text { IN BLOOD } \\
\text { PRESSURE } \\
\pm \text { S.D. }\end{array}$ & $\begin{array}{c}\text { DURATION OF } \\
\text { DROP } \\
\text { (Mean and Range) } \\
\text { (Sec.) }\end{array}$ \\
\hline 2.0 & 3 & $42 \pm 8$ & $173(140-220)$ \\
6.0 & 3 & $53 \pm 14$ & $155(80-230)$ \\
8.0 & 2 & $47 \pm 22$ & $50(30-70)$ \\
\hline
\end{tabular}


Table V Effects of trans-2-(p-chlorophenyl)-N, N-dimethylcyclohexylamine HCL (TH-25) on the blood pressure of rats.

\begin{tabular}{|c|c|c|c|}
\hline $\begin{array}{c}\text { DOSE } \\
(\mathrm{mg} / \mathrm{kg})\end{array}$ & $\begin{array}{c}\text { NUMBER OF } \\
\text { TRLALS }\end{array}$ & $\begin{array}{l}\text { MEAN \% RISE } \\
\text { IN BLOOD } \\
\text { PRESSURE } \\
\text { 土 S. D. }\end{array}$ & $\begin{array}{l}\text { DURATION OF } \\
\frac{\text { RISE }}{\text { (Mean and Range) }} \\
\text { (Sec.) }\end{array}$ \\
\hline 4.0 & 5 & $20 \pm 9$ & $44(30-60)$ \\
\hline 6.0 & 5 & $28 \pm 10$ & $74(40-100)$ \\
\hline 8.0 & 4 & $23 \pm 4$ & $108(90-130)$ \\
\hline
\end{tabular}


Table VI Effects of trans-2-(p-chlorophenyl)-N-methylcyclohexylamine HCL (TH-26) on the blood pressure of rats.

\begin{tabular}{cccc}
$\begin{array}{c}\text { DOSE } \\
(\mathrm{mg} / \mathrm{kg})\end{array}$ & $\begin{array}{c}\text { NUMBER OF } \\
\text { TRIALS }\end{array}$ & $\begin{array}{c}\text { MEAN \% DROP } \\
\text { IN BLOOD } \\
\text { PRESSURE } \\
\pm \text { S. D. }\end{array}$ & $\begin{array}{c}\text { DURATION OF } \\
\text { DROP } \\
\text { (Mean and Range) } \\
\text { (Sec.) }\end{array}$ \\
\hline 2.0 & 2 & $5 \pm 0$ & $25(20-30)$ \\
4.0 & 3 & $13 \pm 3$ & $40(20-50)$ \\
6.0 & 3 & $25 \pm 5$ & $74(40-90)$ \\
8.0 & 3 & $39 \pm 17$ & $237(130-420)$ \\
10.0 & 3 & $39 \pm 14$ & $123(40-200)$ \\
12.0 & 3 & $42 \pm 9$ & $113(50-230)$ \\
14.0 & 2 & $32 \pm 4$ & $155(150-160)$ \\
18.0 & 1 & 38 & 130 \\
\hline
\end{tabular}


Table VII Effects of cis-2-(p-chlorophenyl)-N, N-dimethylcyclohexylamine HCL $(\mathrm{TH}-27)$ on the blood pressure of rats.

\begin{tabular}{cccc}
$\begin{array}{c}\text { DOSE } \\
(\mathrm{mg} / \mathrm{kg})\end{array}$ & $\begin{array}{c}\text { NUMBER OF } \\
\text { TRIALS }\end{array}$ & $\begin{array}{c}\text { MEAN \% DROP } \\
\text { IN BLOOD } \\
\text { PRESSURE } \\
\pm \text { S. D. }\end{array}$ & $\begin{array}{c}\text { DURATION OF } \\
\text { DROP } \\
\text { (Mean and Range) } \\
\text { (Sec.) }\end{array}$ \\
\hline 2.0 & 2 & $20 \pm 8$ & $25(20-30)$ \\
4.0 & 3 & $28 \pm 5$ & $33(30-40)$ \\
6.0 & 3 & $46 \pm 4$ & $90(60-120)$ \\
10.0 & 2 & $57 \pm 4$ & $130(110-150)$ \\
14.0 & 3 & $43 \pm 2$ & $97(70-110)$ \\
\hline
\end{tabular}


Tracings from kymograph records.
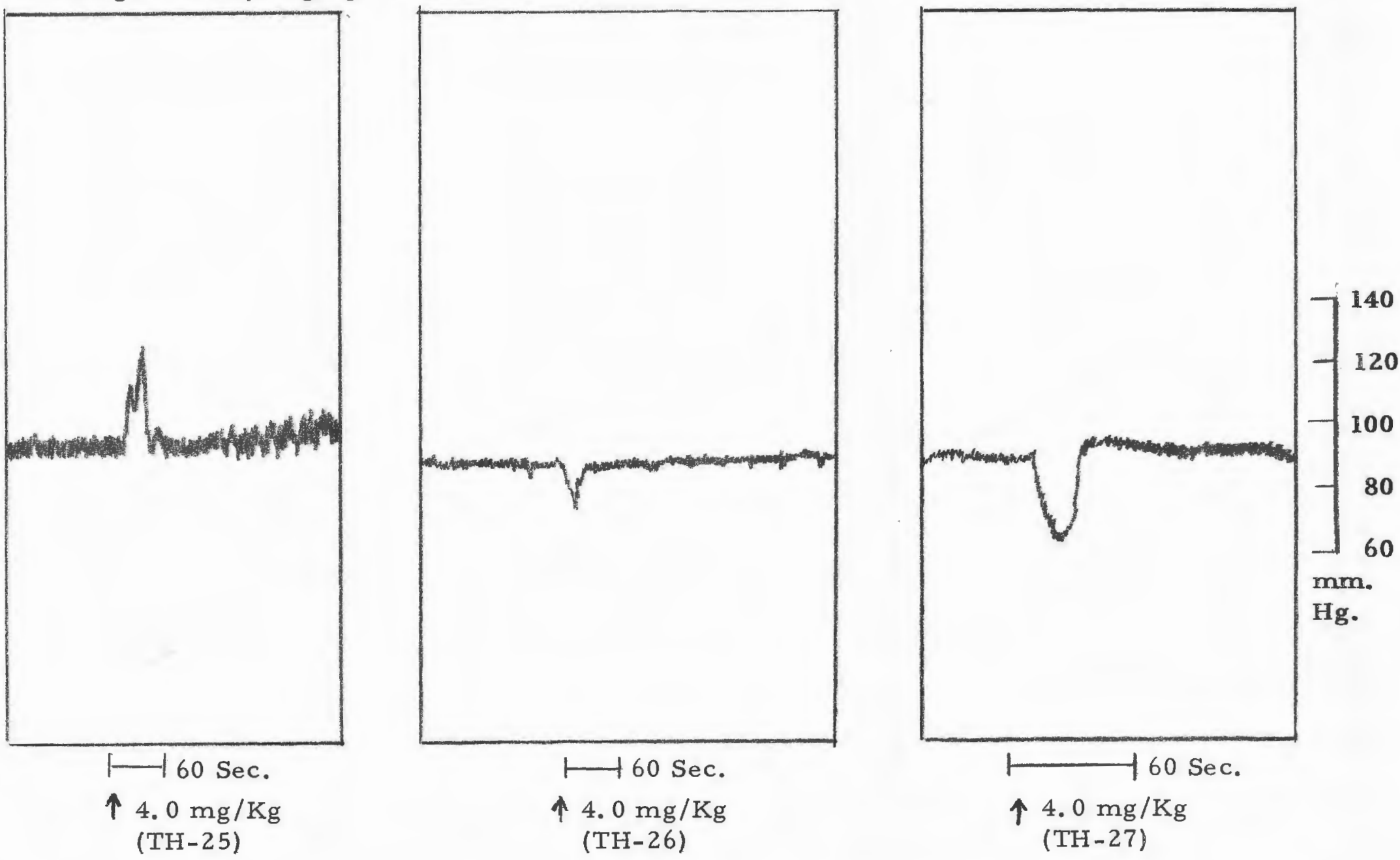

Fig. 3 Rat blood pressure response to each of the cyclohexylamine hydrochlo ride salts $(4.0 \mathrm{mg}$. $/ \mathrm{Kg}$.). 


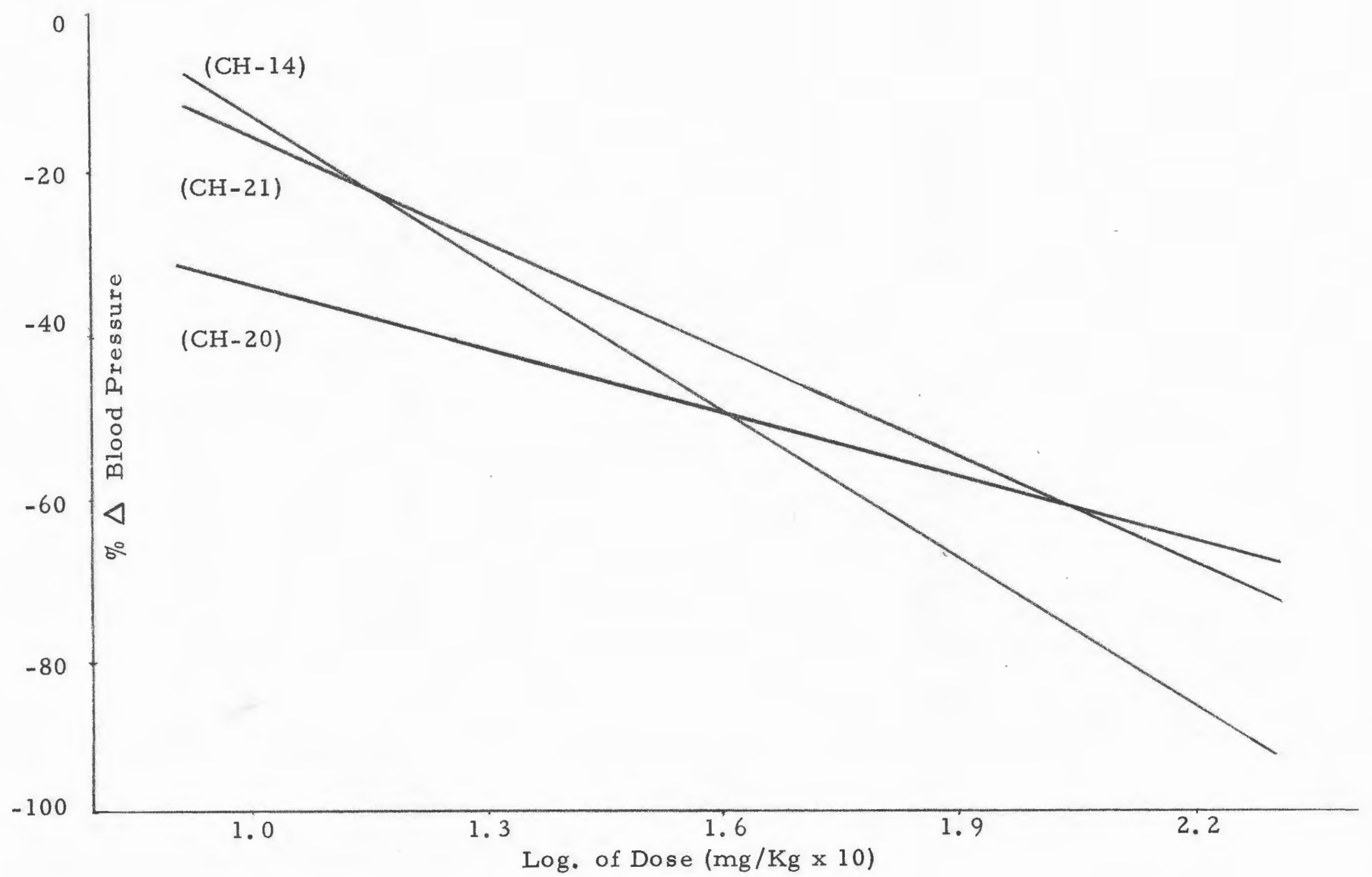

Fig. 4 A comparison of the hypotensive effects produced by the cyclohexanol derivatives. 


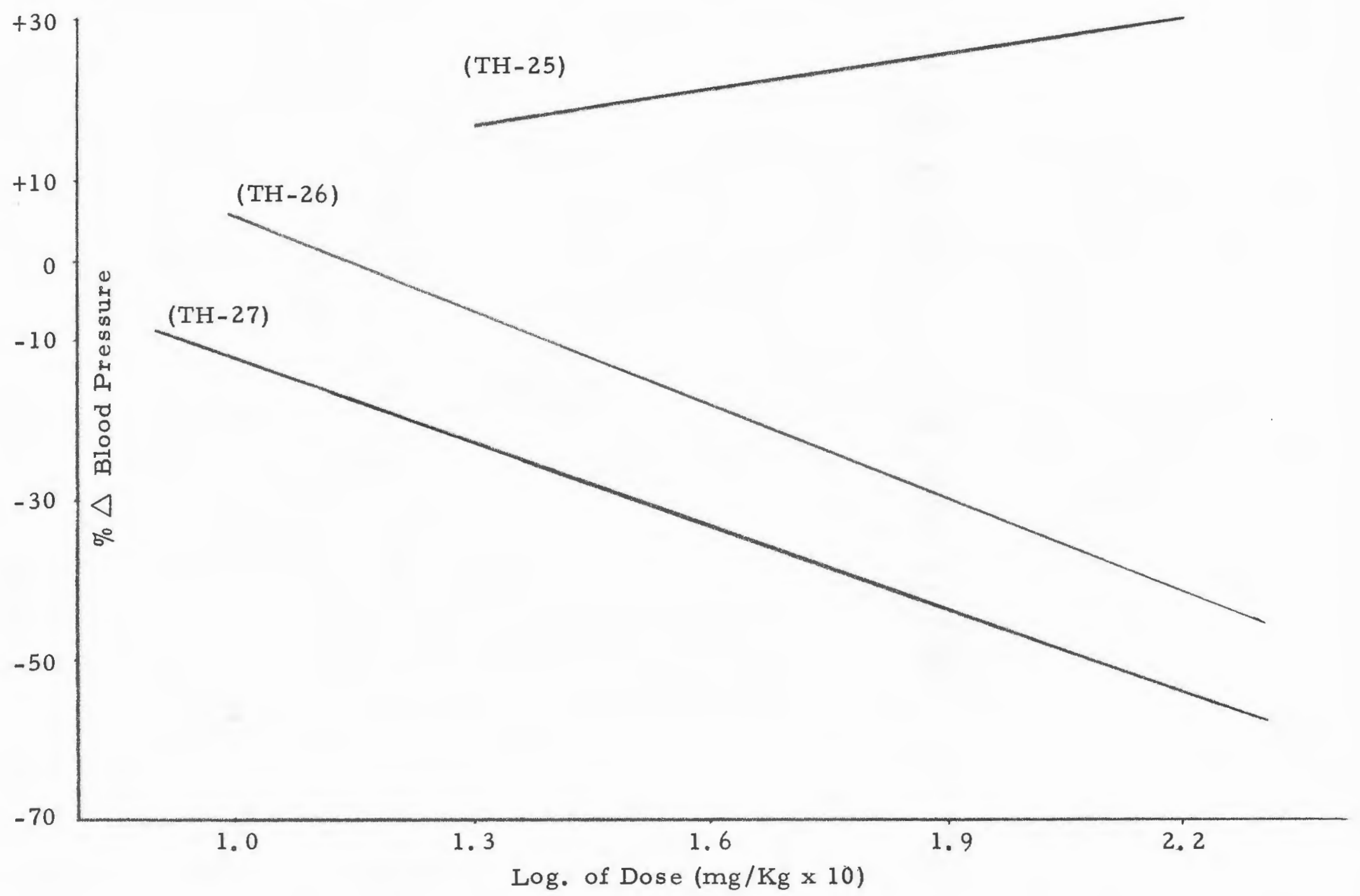

Fig. 5 A comparison of the blood pressure effects produced by the cyclohexylamine hydrochloride derivatives. 
Table VIII A comparison of the $\mathrm{ED}_{50}$ (hypotensive) of the non-ethynyl cyclohexanol derivatives and the cyclohexylamine derivatives on the blood pressure of rats ${ }^{2}$

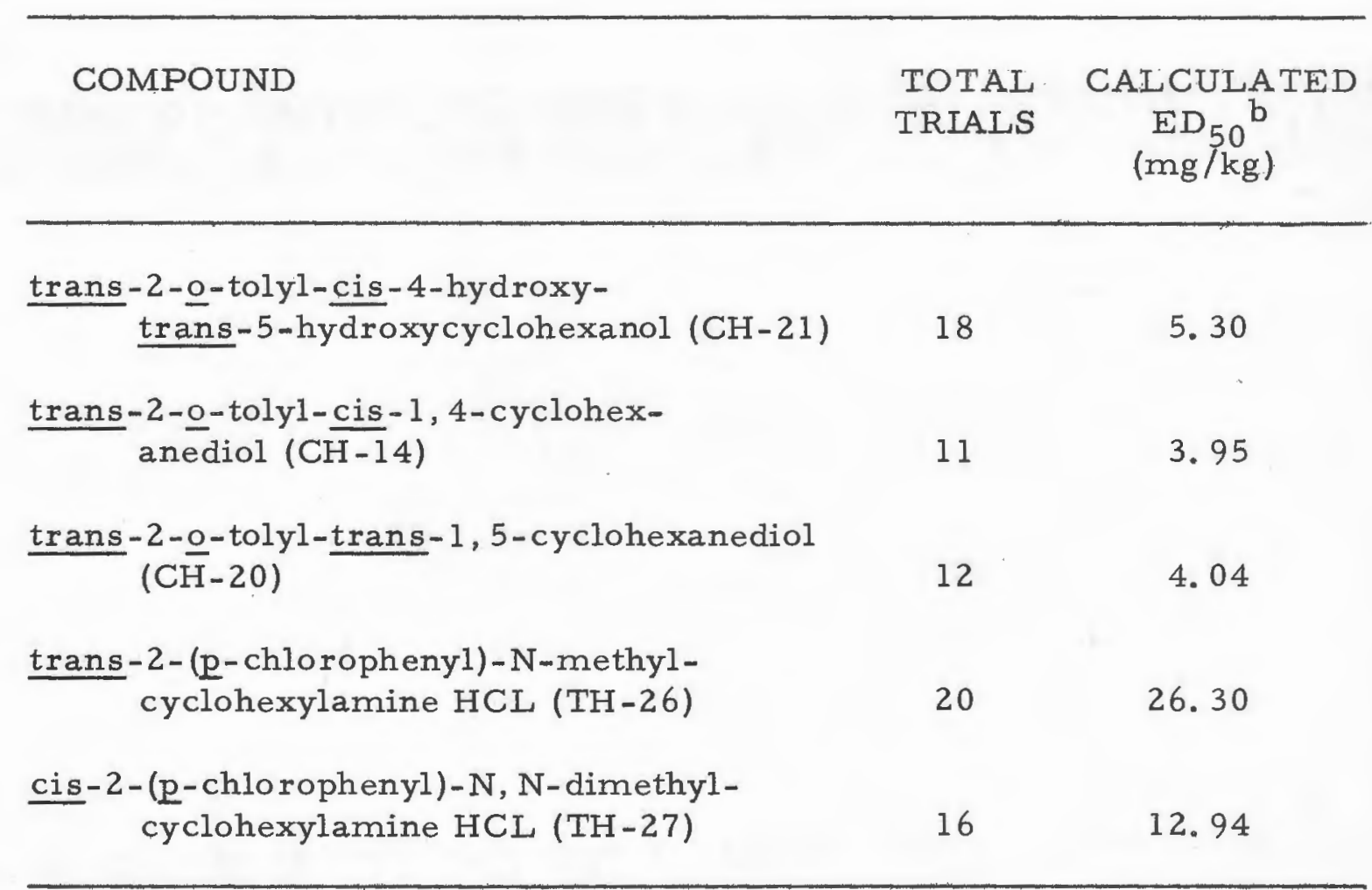

a See Figs. 4 and 5.

b derived from the regression line formula which was obtained from the analysis of results on the IBM 1410 Computer. 
2. Effects of the Cyclohexanol Derivatives and the Cyclohexylamine Hydrochloride Salts on the Contractility of the Isolated Guinea Pig Heart.

\section{a.) Experimental Procedures}

Guinea pigs of either sex weighing between 465 and $989 \mathrm{~g}$. were sacrificed by cervical dislocation. Following removal of the sternum and retraction of the ribs, the heart was prepared in the following manner:

1. Clamping and cutting distally, the descending aorta in the a rea of the diaphragm.

2. Severing the intercostal, innominate, and left subclavian arteries, thus freeing the aorta.

3. Severing the superior and inferior venae cavae.

After severing the trachea, the heart was rapidly removed with the lungs attached and transferred to a dish of oxygenated perfusion solution at room temperature. A glass cannula was inserted into the aorta and tied firmly in place so that its' tip was just proximal to the innominate artery and distal to the coronary ostia. Several $\mathrm{ml}$ of warm oxygenated perfusion solution combined with $0.1 \mathrm{ml}$ of a 1:000 solution of heparin sodium were gently forced into the coronary arteries to remove residual blood and minimize the possibility of the formation of small clots within these vessels. 
The cannulated heart was then transferred to an AndersonCraver heart perfusion apparatus ${ }^{1}$, modified by maintaining a constant fluid level in the perfusion well. The siphoned fluid was collected with the aid of a pump and returned to the perfusion fluid reservoir, through a glass tube placed in the upper end of the well, which projects above the warming chamber.

Following stabilization of the preparation under a perfusion head pressure of $54 \mathrm{~cm}$ of water and at a constant temperature of $37.5^{\circ} \mathrm{C}$ maintained by a water bath, all extraneous tissue including the pericardium was dissected free. A stainless steel hook was inserted into the ventricular musculature at the heart's apex and the lower portion of the apparatus secured in place. By means of a cotton thread running from the hook, through a pulley system to a recording lever, the cardiac contractions were recorded on a slowly moving smoked kymograph.

The perfusion solution used in all experiments was that recommended by Chenoweth and Koelle (1946) slightly modified by Smookler and DeFeo (1962).

1. Metro Industries, Long Island City, N. Y. 
The composition of the perfusion solution expressed in grams per liter and in millimoles per liter is as follows:

$\begin{array}{llr} & \frac{\mathrm{g} / 1}{\mathrm{mM} / 1} \\ \mathrm{NaCl} & 7.0 & 119.8 \\ \mathrm{KCl} & 0.42 & 5.63 \\ \mathrm{CaCl2} & 0.24 & 2.16 \\ \mathrm{MgSO} 4 & 0.52 & 2.11 \\ \text { dextrose } & 1.80 & 10.00 \\ \mathrm{NaHCO} 3 & 2.1 & 25.00\end{array}$

Three liters of stock solution containing $350 \mathrm{~g}$. sodium chloride, 12.0

21.0 g. potassium chloride, 16.0 g. calcium chloride and $26.0 \mathrm{~g}$. magnesium sulfate ${ }^{1}$ were prepared and stored at room temperature. The final perfusion fluid was prepared for each experiment by taking $120 \mathrm{ml}$. of stock solution, $3.6 \mathrm{~g}$. dextrose and $4.2 \mathrm{~g}$. of sodium bicarbonate and sufficient deionized water to make two liters of solution. This was immediately oxygenated with a mixture of 95 per cent oxygen and 5 per cent carbon dioxide. The $\mathrm{pH}$ of the final solution was 7.9 . Throughout each experiment, the effluent perfusate was not recycled, but was collected and discarded.

After recording normal cardiac contractions, injections (trials)

1. The heptahydrate salt was used throughout this work. 
were made via an injection spiral connected to the perfusion canal, and displaced (washed) with a volume of perfusate equal to that held by the spiral (1.5 ml.). At least one subsequent wash followed recovery to assure complete introduction of the entire dose of test material. Only one compound was tested in each experiment, and not more than five injections were made during one experiment. Succeeding doses were administered not less than ten minutes from the time of recovery of the previous dose. In the case of the ethynyl derivatives of cyclohexanol the procedure was modified to include the injection of 50 per cent polyethylene glycol (PEG) 400 as a control at the beginning and end of each experiment. The volume of the control equaled that of the drug and solvent combined for a particular dose.

A depression of 95 per cent or more from the normal was considered to be cardiac arrest, and recovery was allowed to take place spontaneously. Once again dose and response were subjected to linear regression computations carried out by the IBM 1410 computer. The results were plotted and the dose capable of producing a 95 per cent negative inotropic response calculated.

In two experiments involving trans $-2-(\mathrm{p}-\mathrm{chlorophenyl)}-\mathrm{N}, \mathrm{N}-$ dimethylcyclohexylamine hydrochloride (TH-25) and trans-2(p-chlorophenyl)-N-methylcyclohexylamine hydrochloride ( $\mathrm{TH}-26)$ respectively, an indication of the per cent decrease in coronary flow 
was obtained by recording the time required to collect $1.0 \mathrm{ml}$. of effluent perfusate before and during the observed maximum cardiac depression. In another experiment, the antagonistic effect of the calcium ion on the negative inotropic response to $1.0 \mathrm{mg}$. of 1 -ethynylcis-2-o-tolylcyclohexanol (AH-65) was recorded. During maximum cardiac depression, various concentrations of calcium chloride were injected at intervals.

The indices of activity used to compare the different compounds were as follows:

(1) The incidence and duration of cardiac arrest at a particular dose.

(2) The incidence and per cent of cardiac depression if no arrest occurred.

(3) The time of recovery to 50 per cent of the normal cardiac contraction.

b. ) Results

The results include the following:

(1) Effects of the cyclohexanol derivatives and the cyclohexylamine hydrochloride salts on the isolated guinea pig heart (Tables IX to XV).

(2) A comparison of the cyclohexanol derivatives and the cyclohexylamine hydrochloride salts on the isolated guinea pig heart 
(Table XVI; Fig. 11).

(3) The antagonistic effect of various calcium ion concentrations on the negative inotropic response to $1.0 \mathrm{mg}$. of 1 -ethynylcis-2-o-tolylcyclohexanol (AH-65) (Fig. 7).

(4) Three trials using $1.0 \mathrm{mg}$ of trans-2-o-tolyl-cis-4-hydroxytrans-5-hydroxycyclohexanol produced a mean decrease in amplitude of cardiac contraction of only 10 per cent with a standard deviation of 6. Due to insufficient compound, the higher dosage levels could not be investigated.

(5) Trials using $0.5 \mathrm{mg}$ of trans $-2-(\mathrm{p}-$ chlorophenyl) $-\mathrm{N}, \mathrm{N}-$ dimethylcyclohexylamine hydrochloride ( $\mathrm{TH}-25)$ and trans2-(p-chlorophenyl)-N-methylcyclohexylamine hydrochloride (TH-26) showed a mean per cent increase in the time required to collect $1.0 \mathrm{ml}$ of effluent perfusate of 100 per cent and 88 per cent respectively. The mean control time to collect $1.0 \mathrm{ml}$ of effluent perfusate was 8 seconds for both compounds The former compound showed an increase in mean time of 8 seconds and the latter compound an increase of 7 seconds. 
Table IX Effects of trans-2-o-tolyl-cis-1,4-cyclohexanediol (CH-14) on the isolated guinea pig heart.

\begin{tabular}{|c|c|c|c|c|c|}
\hline $\begin{array}{c}\text { DOSE } \\
(\mathrm{mg})\end{array}$ & $\begin{array}{l}\% \text { P. E. G. } \\
\text { DOSE VOL. } \\
\text { (ml) }\end{array}$ & $\begin{array}{l}\text { CARDIAC ARREST } \\
\text { ARRESTS/TRIALS }\end{array}$ & $\begin{array}{l}\text { DURATION } \\
\text { OF ARREST } \\
\text { (Mean and } \\
\text { range) } \\
\text { (Sec.) }\end{array}$ & $\begin{array}{c}\text { MEAN \% } \\
\text { DEPRESSION } \\
\pm \text { S. D. } \\
\text { (if no arrest) }\end{array}$ & $\begin{array}{c}\text { TIME OF } 50 \% \\
\text { RET URN } \\
\text { (Mean and } \\
\text { range) } \\
\text { (Sec.) }\end{array}$ \\
\hline 0.5 & $0 / 0.14$ & $0 / 2$ & - & $23 \stackrel{+}{-} 11$ & - \\
\hline 1.0 & $0 / 0.29$ & $0 / 5$ & - & $33^{+}-13$ & - \\
\hline 2.0 & $0 / 0.40$ & $0 / 3$ & - & $57^{+}-5$ & $9(6-10)$ \\
\hline 3.0 & $0 / 0.60$ & $0 / 3$ & - & $61 \pm 9$ & $8(2-12)$ \\
\hline 4.0 & $0 / 0.80$ & $1 / 2$ & 12 & 81 & $87(40-134)$ \\
\hline
\end{tabular}

a per cent polyethylene glycol 
Table X Effects of trans-2-o-tolyl-trans-1,5-cyclohexanediol (CH-20) on the isolated guinea pig heart.

\begin{tabular}{|c|c|c|c|c|c|}
\hline $\begin{array}{l}\text { DOSE } \\
(\mathrm{mg})\end{array}$ & $\begin{array}{l}\% \text { P. E. G. } \\
\text { DOSE VOL. } \\
\quad(\mathrm{ml})\end{array}$ & $\begin{array}{l}\text { CARDIAC ARREST } \\
\text { ARRESTS/TRIALS }\end{array}$ & $\begin{array}{c}\text { DURATION } \\
\text { OF ARREST } \\
\text { (Mean and } \\
\text { range) } \\
\text { (Sec.) }\end{array}$ & $\begin{array}{c}\text { MEAN \% } \\
\text { DEPRESSION } \\
\pm \text { S. D. } \\
\text { (if no arrest) }\end{array}$ & $\begin{array}{c}\text { TIME OF } 50 \% \\
\text { RETURN } \\
\text { (Mean and } \\
\text { range) } \\
\text { (Sec.) }\end{array}$ \\
\hline 1.0 & $0 / 0.10$ & $0 / 2$ & - & $10 \pm 7$ & - \\
\hline 3.0 & $0 / 0.30$ & $1 / 3$ & 11 & $93 \pm 1$ & $21(14-27)$ \\
\hline 4.0 & $0 / 0.40$ & $3 / 3$ & $15(3-28)$ & - & $24(9-38)$ \\
\hline
\end{tabular}

a per cent polyethylene glycol 
Table XI Effects of 1-ethynyl-trans-2-0-tolylcyclohexanol (AH-64) on the isolated guinea pig heart.

\begin{tabular}{|c|c|c|c|c|c|}
\hline $\begin{array}{l}\text { DOSE } \\
(\mathbf{m g})\end{array}$ & $\begin{array}{l}\% \text { P. E. G. } \\
\text { DOSE VOL. } \\
\text { (ml) }\end{array}$ & $\begin{array}{l}\text { CARDIAC ARREST } \\
\text { ARRESTS/TRIALS }\end{array}$ & $\begin{array}{c}\text { DURATION } \\
\text { OF ARREST } \\
\text { (Mean and } \\
\text { range) } \\
\text { (Sec.) }\end{array}$ & $\begin{array}{c}\text { MEAN \% } \\
\text { DEPRESSION } \\
\text { IS. D. } \\
\text { (if no arrest) }\end{array}$ & $\begin{array}{l}\text { TIME OF } 50 \% \\
\text { RETURN } \\
\text { (Mean and } \\
\text { range) } \\
\text { (Sec.) }\end{array}$ \\
\hline 0.5 & $50 / 0.05$ & $0 / 3$ & - & $58 \pm 22$ & I. R. \\
\hline 1.0 & $50 / 0.10$ & $0 / 3$ & - & $66 \pm 6$ & $316(258-382)$ \\
\hline 2.0 & $50 / 0.40$ & $0 / 3$ & - & $92 \pm 1$ & $796(366-1676)$ \\
\hline 3.0 & $50 / 0.60$ & $2 / 2$ & - & & N.R. \\
\hline
\end{tabular}

a per cent polyethylene glycol

I. R. - incomplete recovery

N. R. - no recovery 
Tracing from kymograph record.

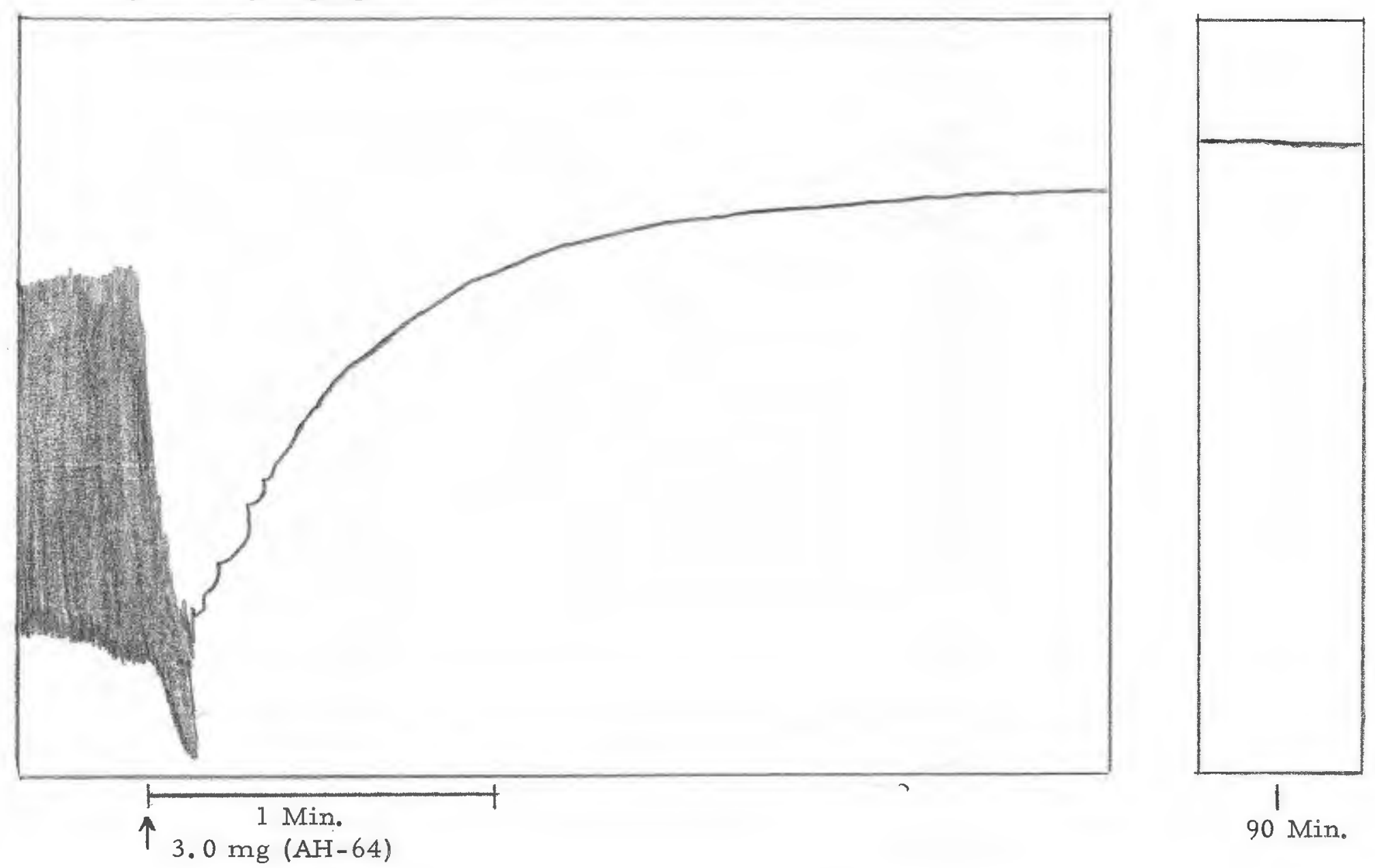

Fig. 6 The cardio-toxic effect of 1-ethynyl-trans-2-o-tolylcyclohexanol (3.0 mg.) on the isolated guinea pig heart. 
Table XII Effects of 1-ethynyl-cis-2-o-tolylcyclohexanol (AH-65) on the isolated guinea pig heart.

\begin{tabular}{|c|c|c|c|c|c|}
\hline $\begin{array}{l}\text { DOSE } \\
(\mathrm{mg})\end{array}$ & $\begin{array}{l}\% \text { P. E. G. } \\
\text { DOSE VOL. } \\
\quad(\mathrm{ml})\end{array}$ & $\begin{array}{l}\text { CARDIAC ARREST } \\
\text { ARRESTS/TRIALS }\end{array}$ & $\begin{array}{c}\text { DURATION } \\
\text { OF ARREST } \\
\text { (Mean and } \\
\text { range) } \\
\text { (Sec.) }\end{array}$ & $\begin{array}{c}\text { MEAN \% } \\
\text { DEPRESSION } \\
\pm \text { S.D. } \\
\text { (if no ar rest) }\end{array}$ & $\begin{array}{c}\text { TIME OF 50\% } \\
\text { RETURN } \\
\text { (Mean and } \\
\text { range) } \\
\text { (Sec.) }\end{array}$ \\
\hline 0.5 & $50 / 0.10$ & $0 / 3$ & - & $68 \pm 9$ & $398(336-452)$ \\
\hline 1.0 & $50 / 0.20$ & $3 / 4$ & $208(181-234)$ & 89 & $329(277-385)$ \\
\hline 2. 0 & $50 / 0.40$ & $3 / 3$ & $586(419-886)$ & - & $1280(980-1658)$ \\
\hline
\end{tabular}

a

per cent polyethylene glycol 
Tracing from kymograph record.
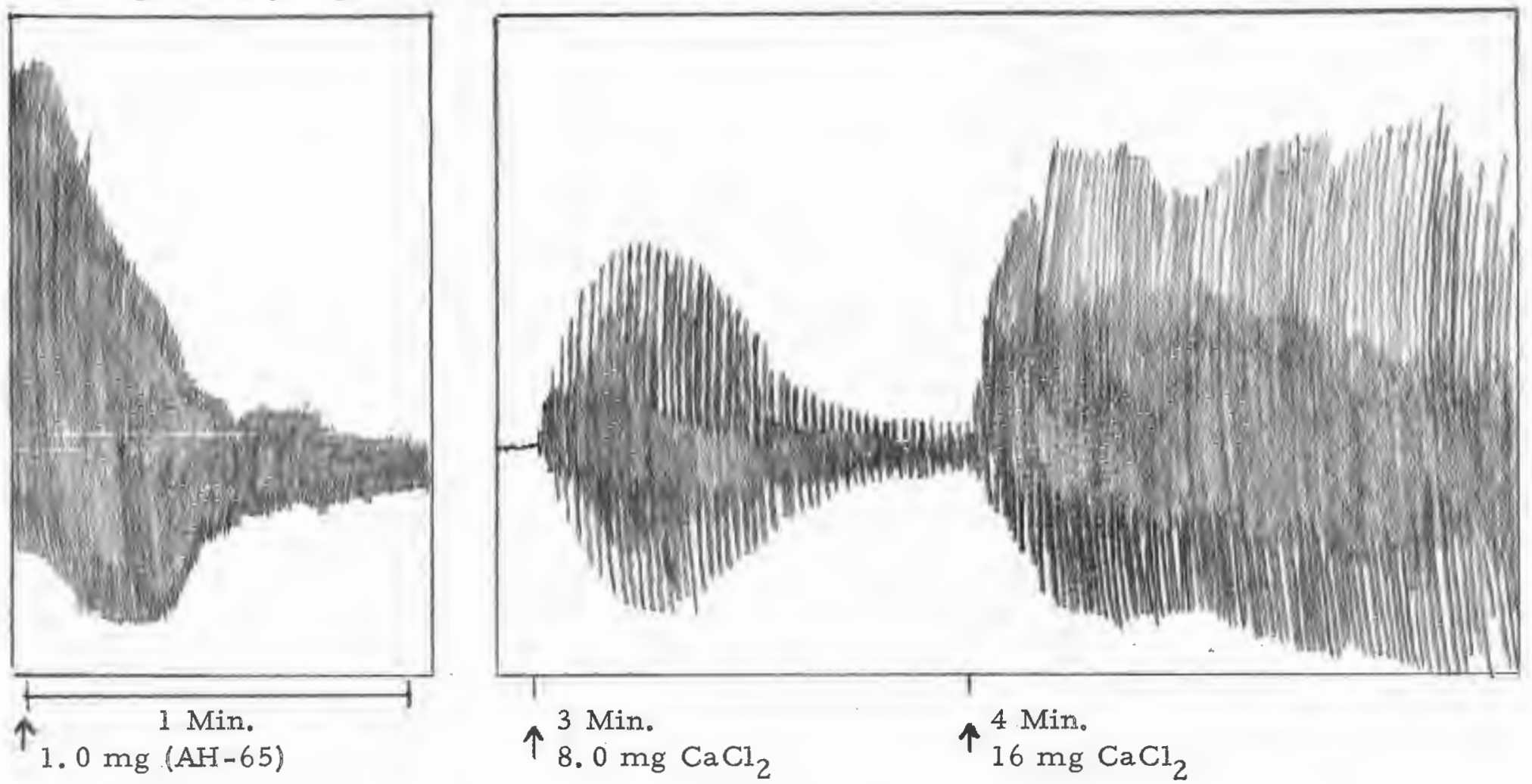

Fig. 7 The effect of calcium chloride $(8.0 \mathrm{mg}$. and $16.0 \mathrm{mg}$.) on the isolated guinea pig heart following $1.0 \mathrm{mg}$ 。 of 1-ethynyl-cis-2o-tolycyclohexanol. 
Table XIII Effect of trans-2-(p-chlorophenyl)-N, N-dimethylcyclohexylamine HCL (TH-25) on the isolated guinea pig heart.

\begin{tabular}{|c|c|c|c|c|c|}
\hline $\begin{array}{l}\text { DOSE } \\
\text { (mg) }\end{array}$ & $\begin{array}{l}\% \text { P. E. G. } \\
\text { DOSE VOL. } \\
\quad(\mathrm{ml})\end{array}$ & $\begin{array}{l}\text { CARDIAC ARREST } \\
\text { ARRESTS/TRIALS }\end{array}$ & $\begin{array}{c}\text { DURATION } \\
\text { OF ARREST } \\
\text { (Mean and } \\
\text { range) } \\
\text { (Sec.) }\end{array}$ & $\begin{array}{c}\text { MEAN \% } \\
\text { DEPRESSION } \\
\pm \text { S. D. } \\
\text { (if no arrest) }\end{array}$ & $\begin{array}{c}\text { TIME OF } 50 \% \\
\text { RETURN } \\
\text { (Mean and } \\
\text { range) } \\
\text { (Sec.) }\end{array}$ \\
\hline 0.25 & $0 / 0.025$ & $0 / 3$ & - & $77 \pm 15$ & $353(183-600)$ \\
\hline 0.5 & $0 / 0.05$ & $1 / 3$ & 46 & $87^{+}-5$ & $202(68-335)$ \\
\hline 1.0 & $0 / 0.10$ & $2 / 3$ & $314(248-380)$ & 92 & $870(645-1190)$ \\
\hline
\end{tabular}

${ }^{\text {a }}$ per cent polyethylene glycol 
Tracing from kymograph record.
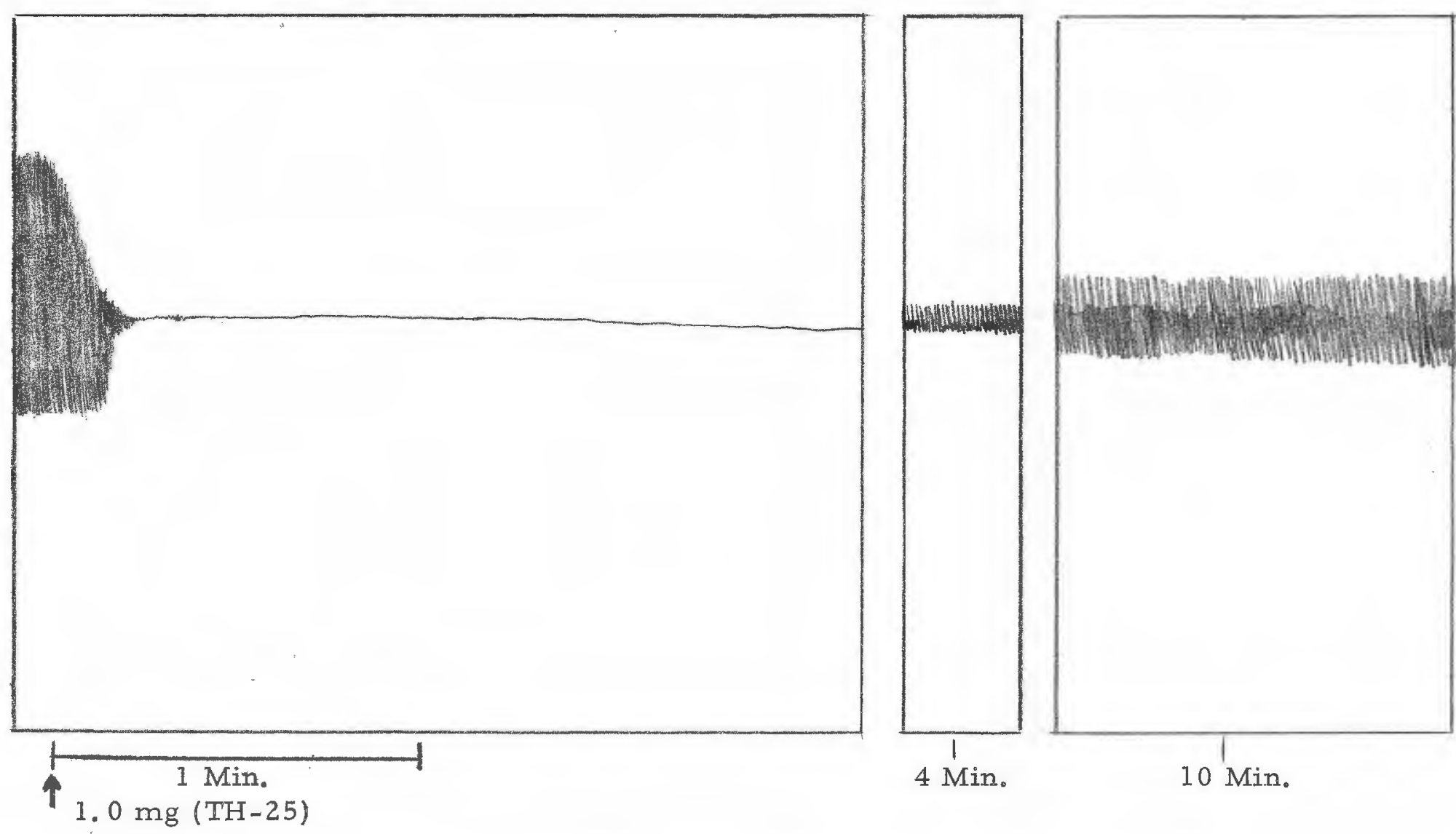

Fig. 8 The effect of trans-2-(p-chlorophenyl)-N, N-dimethylcyclohexylamine hydrochloride $(1.0 \mathrm{mg}$.) on the isolated guinea pig heart. 
Table XIV Effect of trans-2-(p-chlorophenyl)-N-methylcyclohexylamine HCL (TH-26) on the isolated guinea pig heart.

\begin{tabular}{|c|c|c|c|c|c|}
\hline $\begin{array}{l}\text { DOSE } \\
(\mathrm{mg})\end{array}$ & $\begin{array}{l}\% \text { P. E. G. } \\
\text { DOSE VOL. } \\
\quad(\mathrm{ml})\end{array}$ & $\begin{array}{l}\text { CARDIAC ARREST } \\
\text { ARRESTS/TRIALS }\end{array}$ & $\begin{array}{l}\text { DURATION } \\
\text { OF ARREST } \\
\text { (Mean and } \\
\text { range) } \\
\text { (Sec.) }\end{array}$ & $\begin{array}{c}\text { MEAN \% } \\
\text { DEPRESSION } \\
\pm \text { S.D. } \\
\text { (if no arrest) }\end{array}$ & $\begin{array}{l}\text { TIME OF } 50 \% \\
\text { RETURN } \\
\text { (Mean and } \\
\text { range) } \\
\text { (Sec.) }\end{array}$ \\
\hline 0.5 & $0 / 0.50$ & $0 / 3$ & - & $88 \pm 1$ & $556(448-638)$ \\
\hline 1.0 & $0 / 0.10$ & $2 / 3$ & $140(103-176)$ & 78 & $868(554-1049)$ \\
\hline 2.0 & $0 / 0.20$ & $3 / 3$ & $93(42-142)$ & - & $493(372-612)$ \\
\hline
\end{tabular}

a per cent polyethylene glycol 
Tracing from kymograph record.

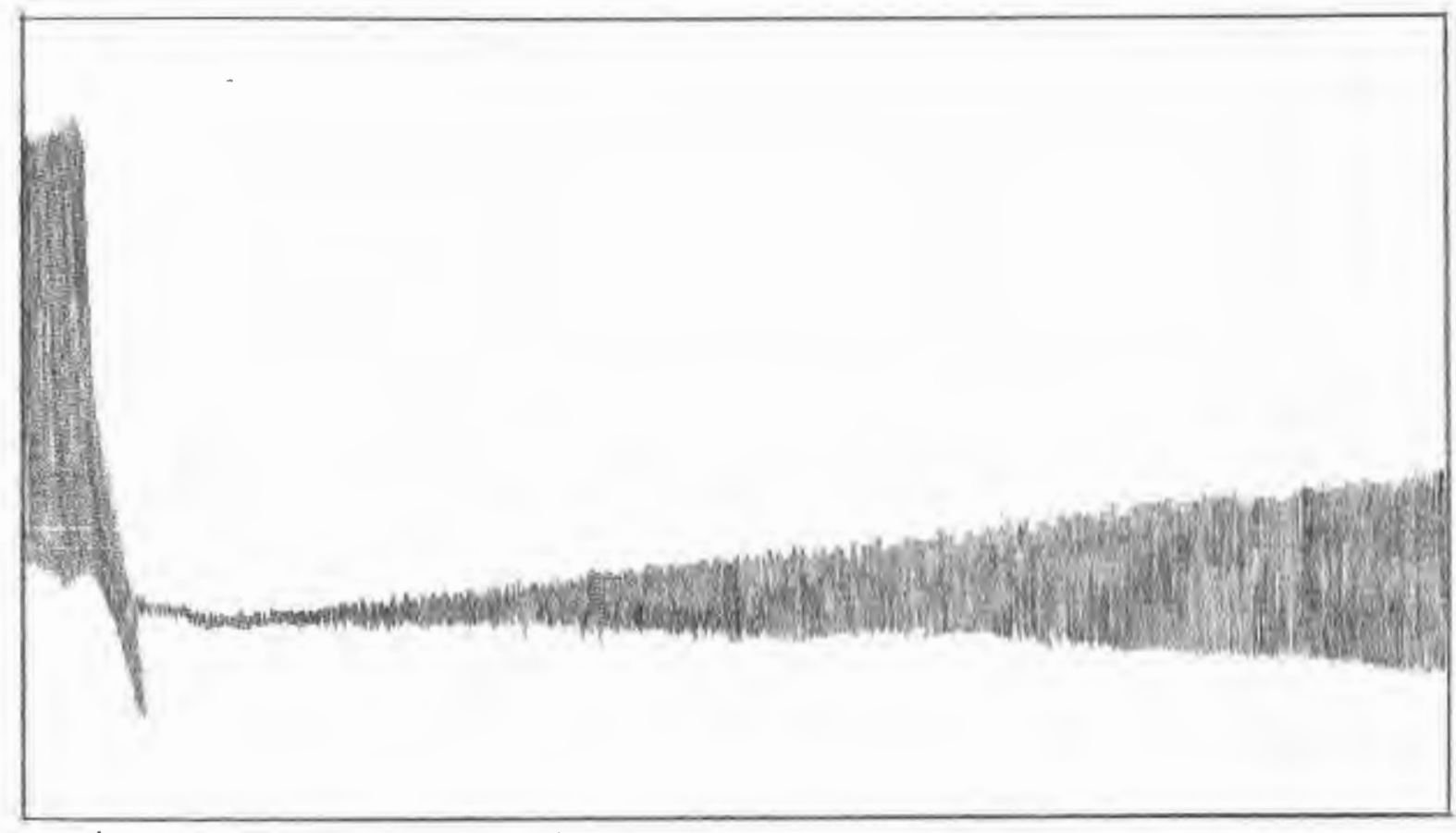

$\uparrow \begin{gathered}1 \mathrm{Min} . \\ 2.0 \mathrm{mg}(\mathrm{TH}-26)\end{gathered}$

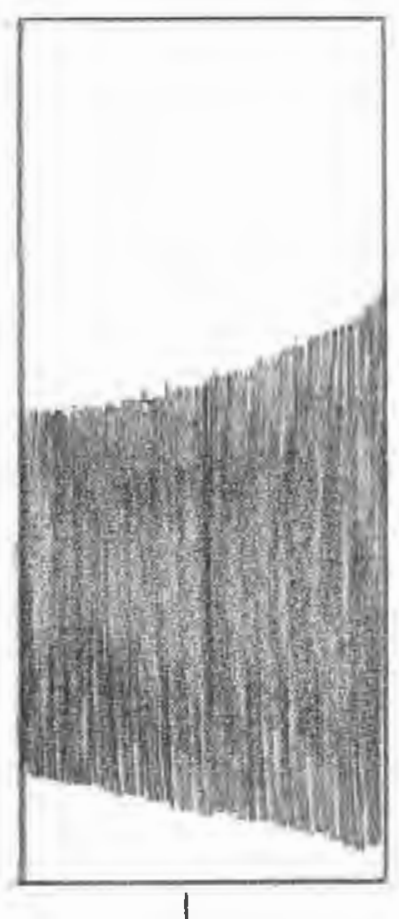

$10 \mathrm{Min}$.

Fig. 9 The effect of trans-2-(p-chlorophenyl)-N-Methylcyclohexylamine hydrochloride $(2.0 \mathrm{mg}$.) on the isolated guinea pig heart. 
Table XV Effect of cis-2-(p-chlorophenyl)-N, N-dimethylcyclohexylamine HCL (TH-27) on the isolated guinea pig heart.

\begin{tabular}{|c|c|c|c|c|c|}
\hline $\begin{array}{r}\text { DOSE } \\
(\mathrm{mg})\end{array}$ & $\begin{array}{l}\% \text { P. E. G. } \\
\text { DOSE VOL. } \\
\quad(\mathrm{ml})\end{array}$ & $\begin{array}{l}\text { CARDIAC ARREST } \\
\text { ARRESTS/TRIALS }\end{array}$ & $\begin{array}{l}\text { DURATION } \\
\text { OF ARREST } \\
\text { (Mean and } \\
\text { range) } \\
\text { (Sec.) }\end{array}$ & $\begin{array}{c}\text { MEAN \% } \\
\text { DEPRESSION } \\
\text { - S.D. } \\
\text { (if no arrest) }\end{array}$ & $\begin{array}{c}\text { TIME OF } 50 \% \\
\text { RETURN } \\
\text { (Mean and } \\
\text { range) } \\
\text { (Sec.) }\end{array}$ \\
\hline 0.25 & $0 / 0.025$ & $0 / 3$ & - & $76 \pm 8$ & $558(509-644)$ \\
\hline 0.5 & $0 / 0.05$ & $0 / 4$ & - & $82 \stackrel{+}{-} 12$ & $411(126-628)$ \\
\hline 1.0 & $0 / 0.10$ & $3 / 3$ & $470(308-636)$ & - & $1205(556-1970)$ \\
\hline
\end{tabular}

a per cent polyethylene glycol 
Tracing from kymograph record.

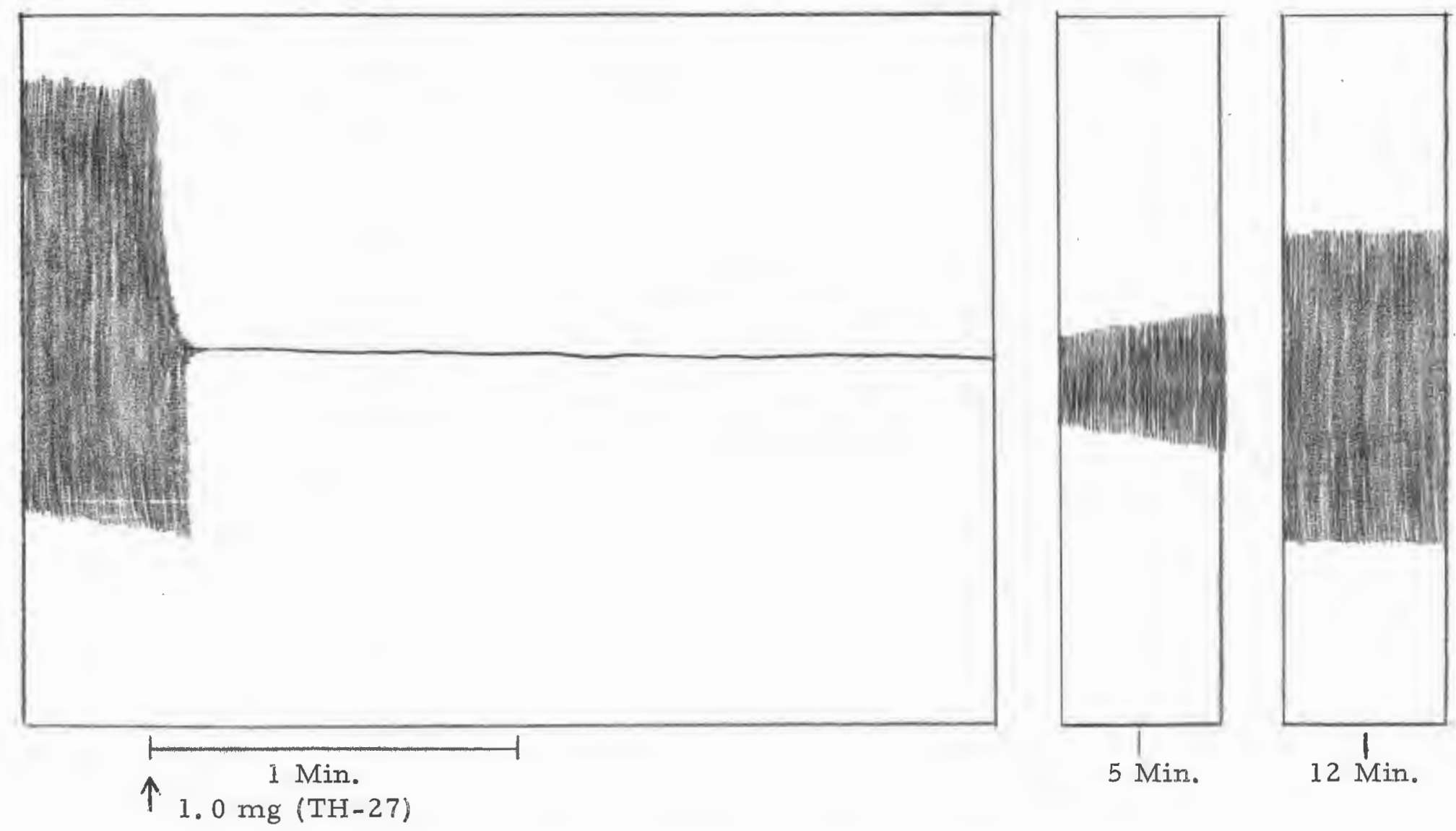

Fig. 10 The effect of cis-2-(p-chlorophenyl)-N, N-dimethylcyclohexylamine hydrochloride $(1.0 \mathrm{mg}$.) on the isolated guinea pig heart. 


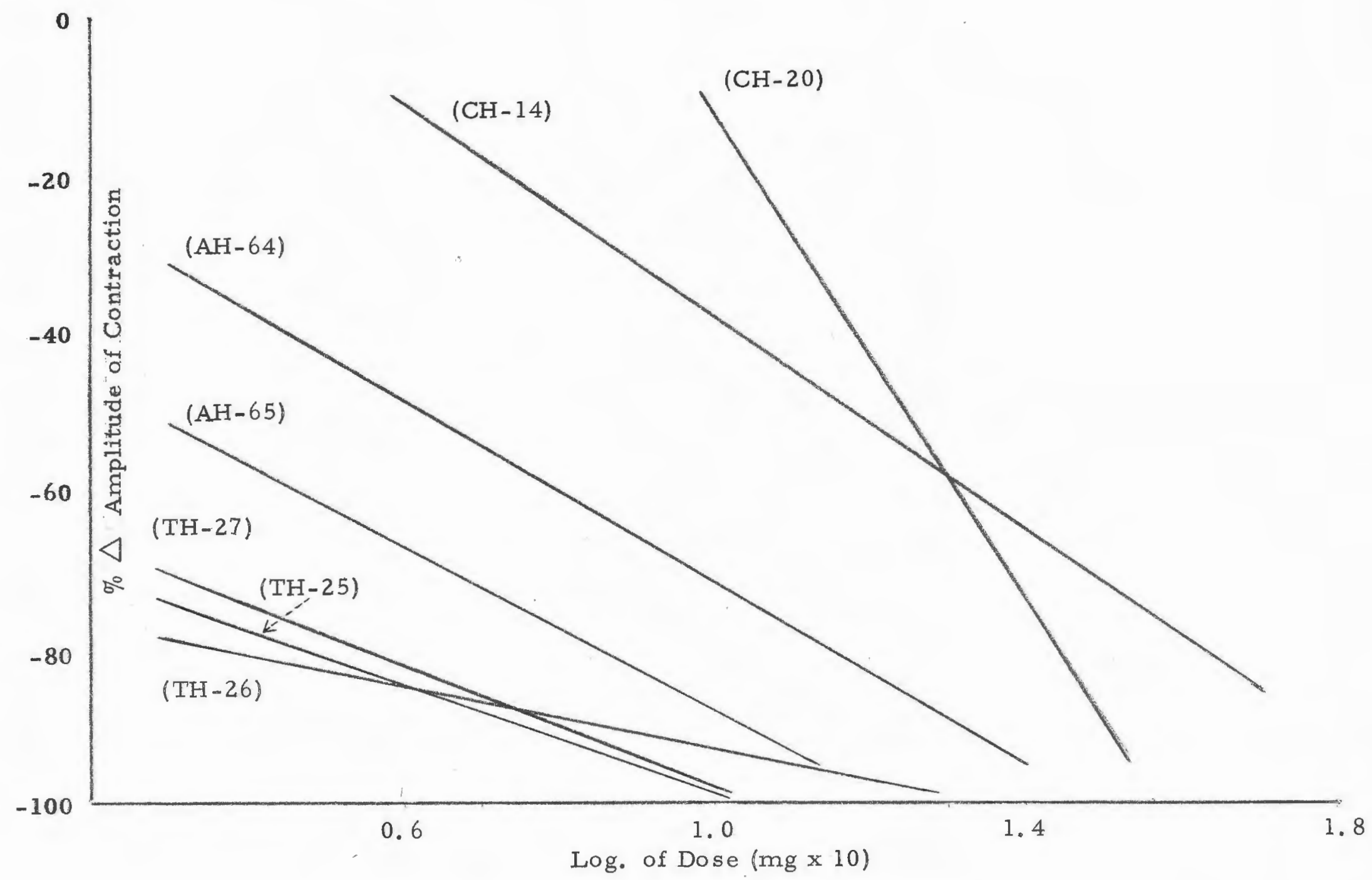

Fig. 11 A comparison of the cardio-inhibitory effects produced by the derivatives of cyclohexanol and cyclohexylamine hydrochloride. 
Table XVI A comparison of the $E D_{95}$ (cardio-inhibitory) of the cyclohexanol and cyclohexylamine derivatives on the isolated guinea pig heart.

\begin{tabular}{|c|c|c|}
\hline COMPOUND & $\begin{array}{l}\text { TOTAL } \\
\text { TRIALS }\end{array}$ & $\begin{array}{l}\text { CALCULATED } \\
{\text { ED } 95^{\mathrm{b}}}_{(\mathrm{mg})}\end{array}$ \\
\hline$\frac{\operatorname{trans}-2-o-\text { tolyl-cis-1, 4-cyclohexanediol }}{(\mathrm{CH}-14)}$ & 15 & 6.80 \\
\hline$\frac{\text { trans - } 2 \text {-o-tolyl-trans-1,5-cyclohexan- }}{\text { ediol }(\mathrm{CH}-20)}$ & 8 & 3.38 \\
\hline $\begin{array}{l}\text { 1-ethynyl-trans-2-o-tolylcyclohexanol } \\
(\mathrm{AH}-64)\end{array}$ & 11 & 2.52 \\
\hline $\begin{array}{l}\text { 1-ethynyl-cis-2-o-tolylcyclohexanol } \\
(\mathrm{AH}-65)\end{array}$ & 10 & 1.33 \\
\hline $\begin{array}{c}\text { trans }-2-(\mathrm{p}-\text { chlo rophenyl) }-\mathrm{N}, \mathrm{N} \text {-dimethyl- } \\
\text { cyclohexylamine HCL }(\mathrm{TH}-25)\end{array}$ & 9 & 0.78 \\
\hline $\begin{array}{r}\text { trans }-2-(\mathrm{p}-\mathrm{chl} \text { orophenyl)-N-methyl- } \\
\text { cyclohexylamine HCL }(\mathrm{TH}-26)\end{array}$ & 8 & 1.19 \\
\hline $\begin{array}{c}\text { cis-2-(p-chlorophenyl)-N, N-dimethyl- } \\
\text { cyclohexylamine HCL (TH-27) }\end{array}$ & 10 & 0.85 \\
\hline
\end{tabular}

${ }^{a}$ See Fig. 11.

$\mathrm{b}$ derived from the regression line formula which was obtained from the analysis of results on the IBM 1410 Computer. 
3. Effects of trans-2-o-Tolyl-trans-1,5-cyclohexanediol (CH-20) and cis $-2-(p-C h l o r o p h e n y l)-N, N$-dimethylcyclohexylamine Hydrochloride (TH-27) on the Contractility of the Isolated Rat Atria.

\section{a.) Experimental Procedures}

Male albino rats weighing 275-350 g. were killed by cervical dislocation and the hearts rapidly excised. The atria were freed of ventricular muscle, fat and connective tissue and suspended vertically in $8 \mathrm{ml}$ of modified Chenoweth-Koelle solution aerated with a mixture of 95 per cent oxygen and 5 per cent carbon dioxide. The bathing solution was of the same composition and $\mathrm{pH}$, as that used in the isola-

ted guinea pig heart experiments and maintained at $29^{\circ} \mathrm{C}$ as suggested by Burn and Vane (1949).

The amplitude of isotonic contractions and the rate of spontaneous beat were recorded under a resting tension of approximately $0.75 \mathrm{~g}$. on a smoked kymograph. Following suspension in the bath, the tissues were allowed to stabilize for twenty to thirty minutes before use. The addition of drugs directly into the $8.0 \mathrm{ml}$ bath did not alter its' volume by more than 4 per cent.

Apart from the ethynyl derivatives, trans-2-o-tolyl-trans-1, 5cyclohexanediol $(\mathrm{CH}-20)$ seemed to give the most consistent effect on the isolated guinea pig heart. For this reason, it was selected for testing on the isolated rat atria. Likewise, cis-2-(p-chlorophenyl)- 
$\mathrm{N}, \mathrm{N}$-dimethylcyclohexylamine (TH-27) hydrochloride was chosen as the representative of the cyclohexylamine derivatives to be tested on the isolated rat atria. A 4.0 per cent solution of calcium chloride was used to determine the possible interactions with the above compounds. All substances were allowed to act on the suspended tis sue for at least three minutes. A minimum of three washes over a period of five minutes were performed between trials, and the tissue allowed an additional five minute recovery period before proceeding to the next trial. Both compounds produced an effect lasting indefinitely. when not washed.

The indices of activity used to evaluate the two compounds were:

1) The per cent change in amplitude of contraction.

2) The change in the beating rate of the preparation.

b.) Results

The results include the following:

(1) The effect of trans-2-o-tolyl-trans-1,5-cyclohexanediol (CH-20) on the isolated rat atria (Fig. 12).

(a.) $4.0 \mathrm{mg}$ of calcium chloride produced an increase in amplitude of contraction of approximately 70 per cent at the end of three minutes reaching a maximum of approximately 300 per cent within thirty seconds. Over the three minute period the rate increased steadily from 160 to 180 beats per minute.

(b. ) $0.6 \mathrm{mg}$ of trans-2-o-tolyl-trans-1,5-cyclohexanediol 


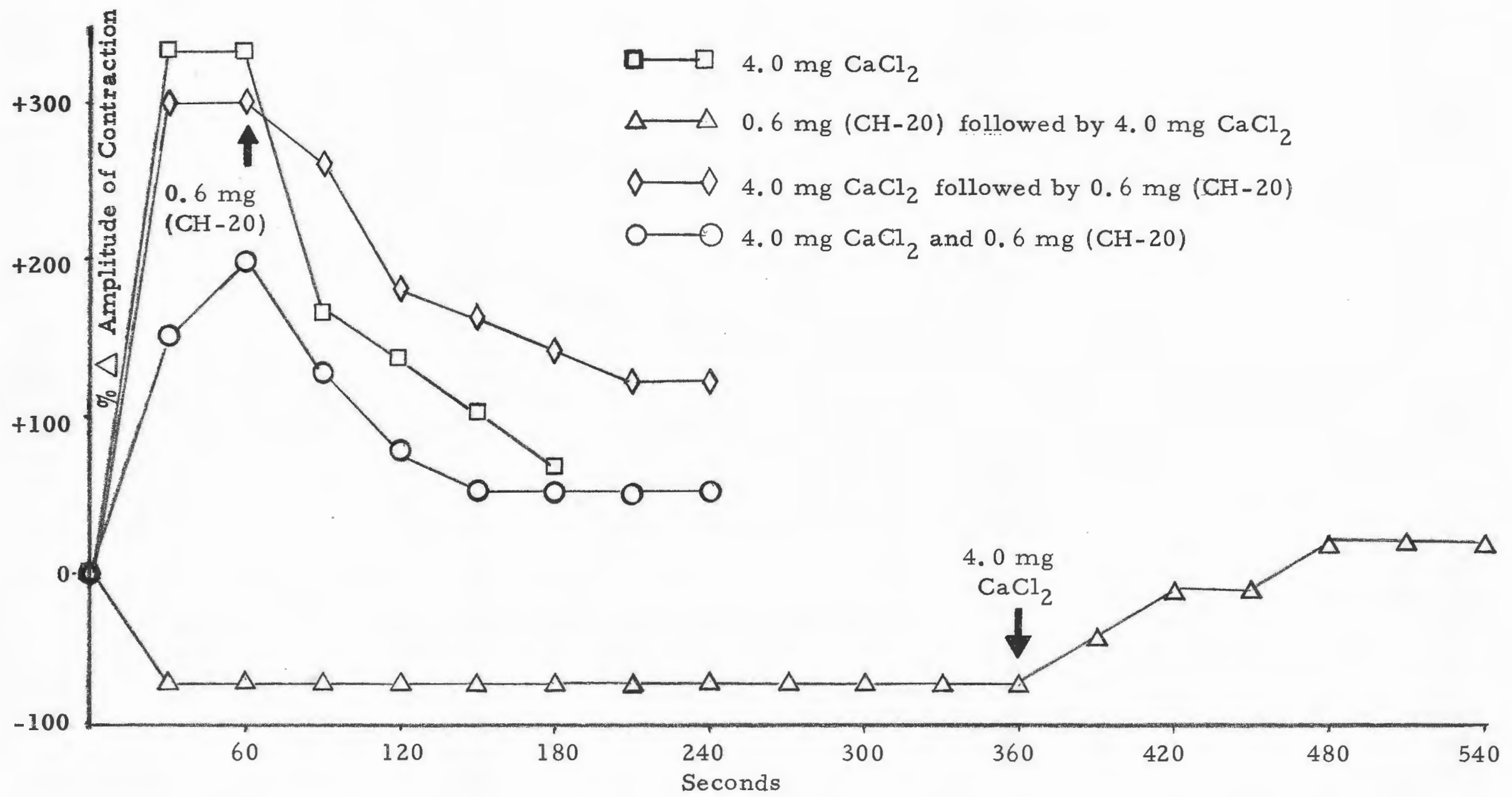

Fig. 12 The effects of trans-2-o-tolyl-trans-1,5-cyclohexanediol (0.6 mg.) and calcium chloride $(4.0 \mathrm{mg}$. $)$ on isolated rat atria. 
$(\mathrm{CH}-20)$ reduced the amplitude of contraction by approximately 70 per cent within thirty seconds, with no apparent change in the rate. At the end of three minutes, a dose of $4.0 \mathrm{mg}$ of calcium chloride restored the amplitude to control level. No change in the rate of contraction was observed over the tis sue exposure time of nine minutes.

$$
\text { (c. ) } 4.0 \mathrm{mg} \text { of calcium chloride again produced an increase }
$$

of approximately 300 per cent within one minute. At this time, $0.6 \mathrm{mg}$ of trans-2-o-tolyl-trans-1,5-cyclohexanediol ( $\mathrm{CH}-20)$ was given. The increase in amplitude was approximately 100 per cent above the control at the end of three minutes. Rate increased steadily from 120 to 140 beats per minute over the total exposure time of four minutes.

(d.) Since it has been suggested that the action of many cardioplegic agents might possibly be the result of the formation of a calcium chelate, $0.6 \mathrm{mg}$ of trans-2-o-tolyl-trans-1,5-cyclohexanediol (CH-20) and $4.0 \mathrm{mg}$ of calcium chloride were combined in a syringe for fifteen minutes prior to administration. When the drug combination was instilled into the bath, amplitude of contraction reached a maximum increase of approximately 200 per cent within one minute. After three minutes the amplitude increase leveled off at 50 per cent. The rate at the end of one and three minutes respectively was 150 and 160 beats per minute.

(2) The effect of cis-2-(p-chlorophenyl)-N, N-dimethylcyclohexylamine hydrochloride ( $\mathrm{TH}-27$ ) on the isolated rat atria (Fig. 13). 


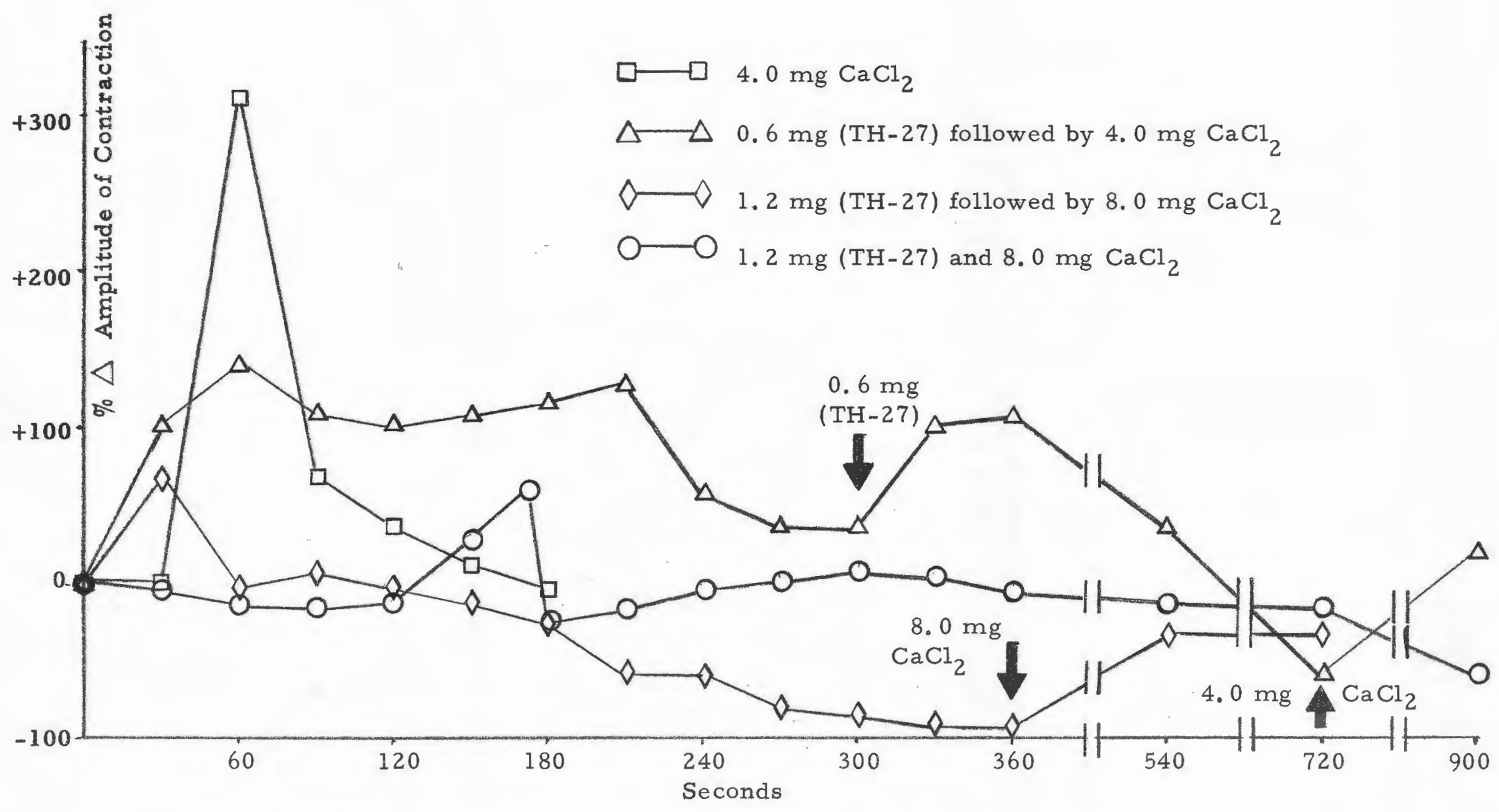

Fig. 13 The effects of cis-2-(p-chlorophenyl)-N, N-dimethylcyclohexylamine hydrochloride $(0.6 \mathrm{mg}$. and $1.2 \mathrm{mg}$. $)$ and calcium chloride $(4.0 \mathrm{mg}$. and $8.0 \mathrm{mg}$. on isolated rat atria. 
(a.) $4.0 \mathrm{mg}$ of calcium chloride produced an increase in amplitude of contraction of approximately 300 per cent within one minute followed by a gradual return to the control level within three minutes. The rate of contraction increased steadily from 140 to 200 beats per minute over the three minute period.

(b. ) $0.6 \mathrm{mg}$ of cis-2-(p-chlorophenyl)-N, N-dimethylcyclohexylamine hydrochloride (TH-27) produced an amplitude increase of approximately 150 per cent within one minute with a gradual reduction to 50 per cent above the control level at the end of five minutes. At this time, a second dose of $0.6 \mathrm{mg}$ of the compound restored the amplitude to approximately 100 per cent above the control level within one minute. The amplitude gradually decreased to 50 per cent below the control level twelve minutes after the first dose of the compound was added. $4.0 \mathrm{mg}$ of calcium chloride given at this time restored the amplitude to the control level at the end of the fifteenth minute. During the first five minutes, the rate decreased from 120 to 70 beats per minute. After the second dose of the compound was given the rate was further reduced to 40 beats per minute. The calcium chloride increased the rate from 40 to 42 beats per minute during the final three minutes of tissue exposure.

$$
\text { (c. ) } 1.2 \mathrm{mg} \text { of cis-2-(p-chlo rophenyl)-N, N-dimethylcyclo- }
$$

hexylamine hydrochloride $(\mathrm{TH}-27)$ produced an increase in amplitude 
of contraction of approximately 75 per cent within thirty seconds, followed by a rapid return to control level at the end of one minute. During the next five minutes the amplitude gradually dropped below the control level by approximately 90 per cent. At the six minute mark, $8.0 \mathrm{mg}$ of calcium chloride restored the amplitude to approximately 30 per cent below the control level. Within the first minute of tissue exposure, the rate decreased from 100 to 90 beats per minute. During the next five minutes the rate fell to 45 beats per minute. The calcium chloride failed to improve the rate as it continued to decrease and at the twelve minute mark was 35 beats per minute. (d. ) $1.2 \mathrm{mg}$ of cis-2-(p-chlo rophenyl)-N, N-dimethylcyclohexylamine hydrochloride ( $\mathrm{TH}-27)$ combined with $8.0 \mathrm{mg}$ of calcium chloride in a syringe for fifteen minutes prior to administration, produced an increase in amplitude of approximately 60 per cent by the end of the first two minutes and fifty seconds. Within the next ten seconds, the amplitude fell to approximately 30 per cent below the control level. The amplitude reached control level within the next two minutes, but gradually fell to approximately 60 per cent below the control at the end of the tissue exposure time of 15 minutes. The rate of contraction increased from 85 to 95 beats per minute within the first ninety seconds. It then declined steadily to 55 beats per minute after three minutes and eventually fell to 38 beats per minute at the end of the fifteen minute period. 
4. Effects of trans-2-(p-Chlorophenyl)-N, N-dimethylcyclohexylamine Hydrochloride (TH-25) on the Blood Pressure of Both the Hexa$\underline{\text { methonium Treated and Reserpine Pretreated Rat. }}$

\section{a.) Experimental Procedures}

The experimental procedures were basically the same as those previously described; (part I of experimental procedures and results). Male albino rats weighing 194-232 g. we re anesthetized with $1.2 \mathrm{~g} / \mathrm{kg}$ of freshly prepared 25 per cent urethane administered intraperitoneally. Following cannulation of the right common carotid, the blood pressure was recorded manometrically on a smoked kymograph at a moderate rate. All injections were made via a needle permanently secured in the left femoral vein. The left common carotid was isolated and a loose ligature passed beneath it. When clamping the left common carotid, the ligature was lifted and a taped bull-dog clamp secured proximal to the bifurcation. Care was taken to avoid unnecessary stretching of the artery and manipulation of the cervical sympathetic and vagus nerves.

Intravenous hexamethonium $(20 \mathrm{mg} / \mathrm{kg})$ was employed for its ${ }^{\mathrm{t}}$ competitive blocking action at the autonomic ganglia. Halpern et al. (1954) showed that this compound markedly depressed the vasopressor reflexes of carotid sinus origin. 
then the following tests were utilized at five minute intervals ${ }^{*}$ :

1.) occlusion of the left common carotid for ten seconds.

2.) epinephrine $(0.06 \mathrm{ml}$ of $1: 100,000$ solution)

3. ) trans -2-(p-chlorophenyl)-N, N-dimethylcyclohexylamine hydrochloride $(\mathrm{TH}-25)(4.0 \mathrm{mg} / \mathrm{kg})$.

4.) hexamethonium (20 $\mathrm{mg} / \mathrm{kg})\left({ }^{*} \mathrm{ten}\right.$ minute pause)

5.) repeat test 1.)

6.) repeat test 2.)

7.) repeat test 3.)

The per cent change in blood pressure produced by trans-2-(p-chlorophenyl)-N, N-dimethylcyclohexylamine ( $\mathrm{TH}-25)$ before and after the administration of hexamethonium was the index of activity studied.

The effect of reserpine pretreatment on the pressor response to trans $-2-(p-c h l o r o p h e n y l)-N, N$-dimethylcyclohexylamine hydrochloride (TH-25) was also studied. $1.0 \mathrm{mg} / \mathrm{kg}$ of reserpine was administered intraperitoneally on three successive days prior to the experiment.

Once again, the preparation was allowed twenty minutes in which to stabilize and then the following tests were utilized at five minute intervals ${ }^{*}$ :

1.) occlusion of the left common carotid for ten seconds.

2.) trans -2-(p-chlorophenyl)-N, N-dimethylcyclohexylamine hydrochloride $(\mathrm{TH}-25)(4.0 \mathrm{mg} / \mathrm{kg})$. 
3.) epinephrine $(0.04 \mathrm{ml}$ of $1: 100,000$ solution)

4.) dibenamine (15.0 $\mathrm{mg} / \mathrm{kg}$.) (*ten minute pause)

5.) repeat test 2.)

6. ) repeat test 3.)

The per cent change in blood pressure produced by trans $-2-(\mathrm{p}-\mathrm{chloro-}$ phenyl)-N, N-dimethylcyclohexylamine hydrochloride (TH-25) before and after the administration of dibenamine was the index of activity studied.

b. ) Results

The results include the following:

(1) The effects of trans-2-(p-chlorophenyl)-N, N-dimethylcyclohexylamine hydrochloride ( $\mathrm{TH}-25)$ on the blood pressure of the hexamethonium treated rat (Figs. 14 and 15).

(a.) Occlusion of the left common carotid for ten seconds produced a transient increase in blood pressure of approximately 22 per cent.

(b. ) Epinephrine $(0.06 \mathrm{ml}$ of $1: 100,000$ solution) produced an increase in blood pressure of approximately 85 per cent with the response lasting sixty seconds.

(c. ) trans $-2-(\mathrm{p}-$ Chlorophenyl) $-\mathrm{N}, \mathrm{N}$-dimethylcyclohexylamine hydrochloride $(\mathrm{TH}-25)(4.0 \mathrm{mg} / \mathrm{Kg})$ produced an increase in blood 
Tracings from kymograph records.
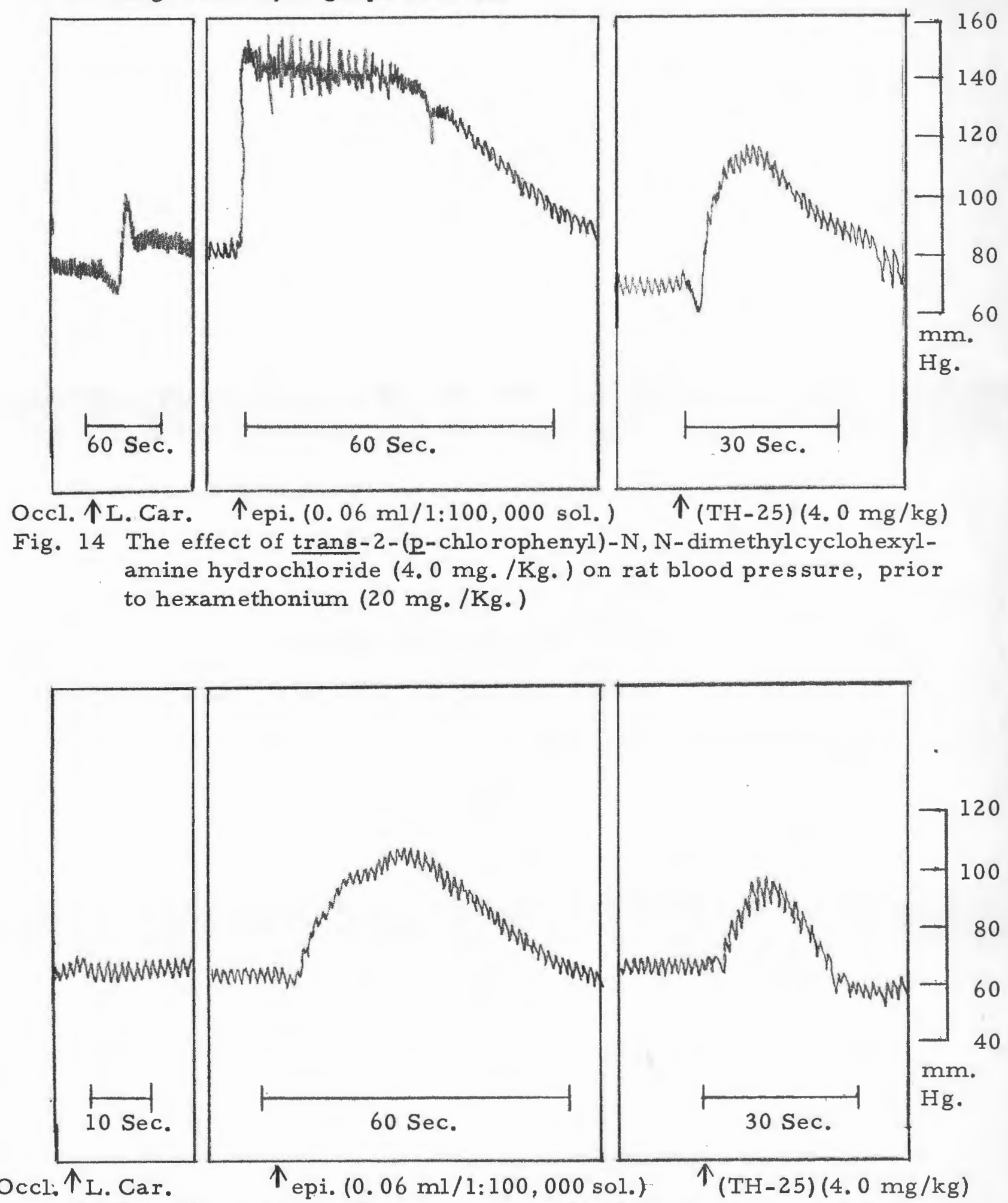

Occl: 个L. Car.

个epi. (0.06 ml/1:100,000 sol.)

T(TH - 25) $(4.0 \mathrm{mg} / \mathrm{kg})$

Fig. 15 The effect of trans-2-(p-chlorophenyl)-N, N-dimethylcyclohexylamine hydrochloride $(4.0 \mathrm{mg}, / \mathrm{Kg}$.) on rat blood pressure, following hexamethonium (20 mg.'/Kg.). 
pressure of approximately 60 per cent with the response lasting sixty seconds.

(d.) Ten minutes after the slow intravenous injection of hexamethonium (20 $\mathrm{mg} / \mathrm{Kg})$, occlusion of the left common carotid for ten seconds failed to elicit the above mentioned pressor response.

(e.) A second injection of epinephrine $(0.06 \mathrm{ml}$ of $1: 100,000$ solution) produced an increase in blood pressure of approximately 60 per cent. Again, the response lasted sixty seconds.

(f. ) A second injection of trans $-2-(\mathrm{p}-$ chlorophenyl)-N, Ndimethylcyclohexylamine hydrochloride $(\mathrm{TH}-25)(4.0 \mathrm{mg} / \mathrm{Kg})$ produced an increase in blood pressure of approximately 42 per cent with the response lasting thirty seconds.

(2) The effects of trans-2-(p-chlorophenyl)-N, N-dimethylcyclohexylamine hydrochloride (TH-25) on the blood pressure of the reserpine pretreated rat (Figs. 16 and 17).

(a, ) Occlusion of the left common carotid for ten seconds failed to produce any alteration in the blood pressure.

(b. ) trans-2-(p-Chlorophenyl)-N, N-dimethylcyclohexylamine hydrochloride $(\mathrm{TH}-25)(4.0 \mathrm{mg} / \mathrm{Kg})$ produced a pressor response of approximately 42 per cent, with a duration of ninety seconds.

(c.) Epinephrine (0.04 ml of 1:100,000 solution) produced an increase in blood pressure of approximately 32 per cent with the 
Tracings from kymograph records.

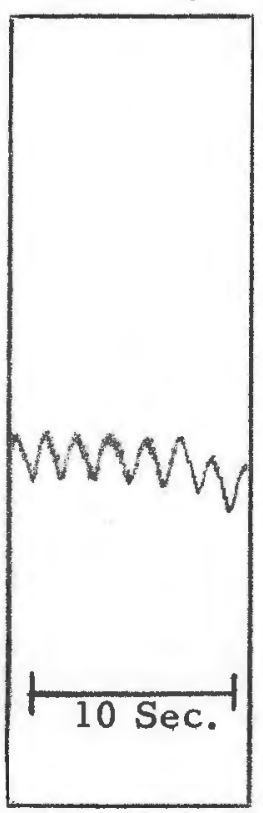

Occl. 个 L. Car.

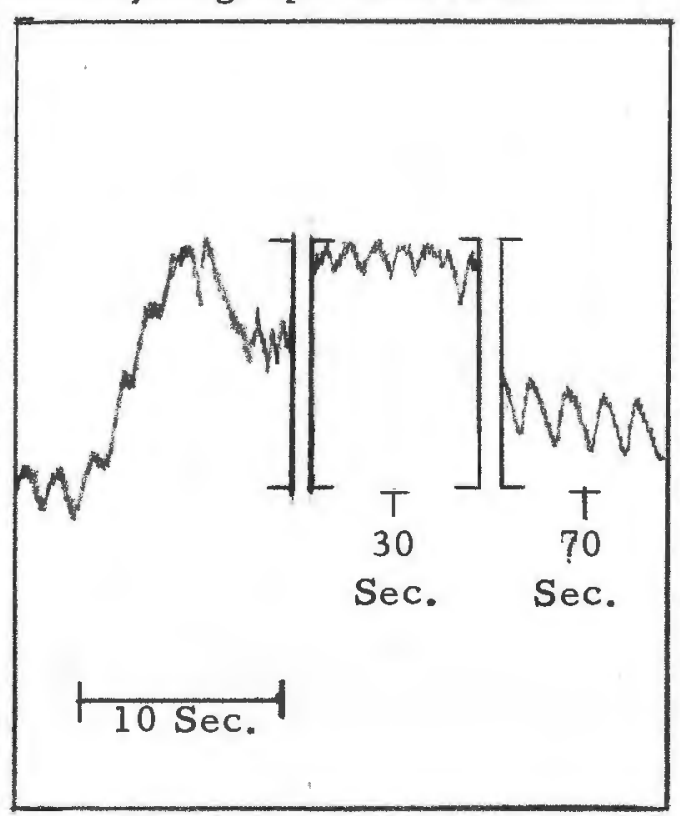

个 (TH $\div 25)(4.0, \mathrm{mg} / \mathrm{kg})$

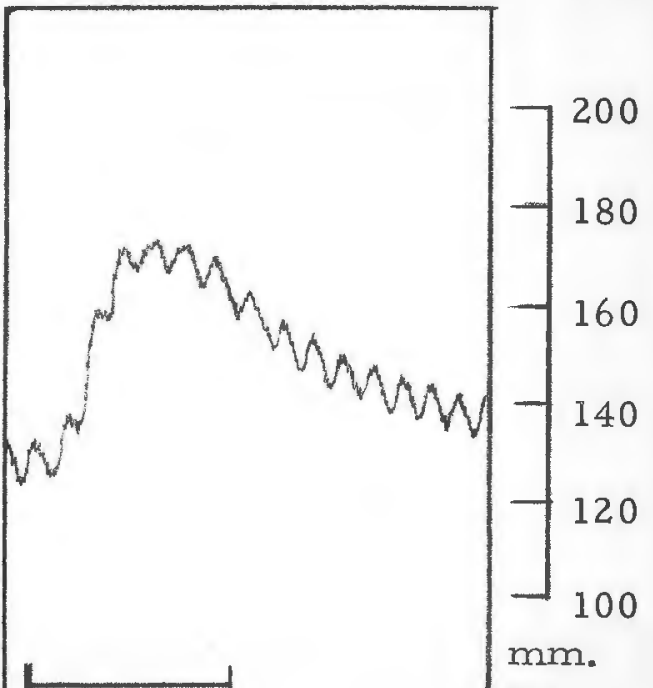

$\mathrm{Hg}$.

Fig. 16 The effect of trans-2-(p-chlorophenyl)-N, N-dimethylcyclohexylamine hydrochloride $(4.0 \mathrm{mg}$. $/ \mathrm{Kg}$.) on the blood pressure of the reserpine pretreated rat prior to dibenamine $(15 \mathrm{mg}$. $/ \mathrm{Kg}$.).

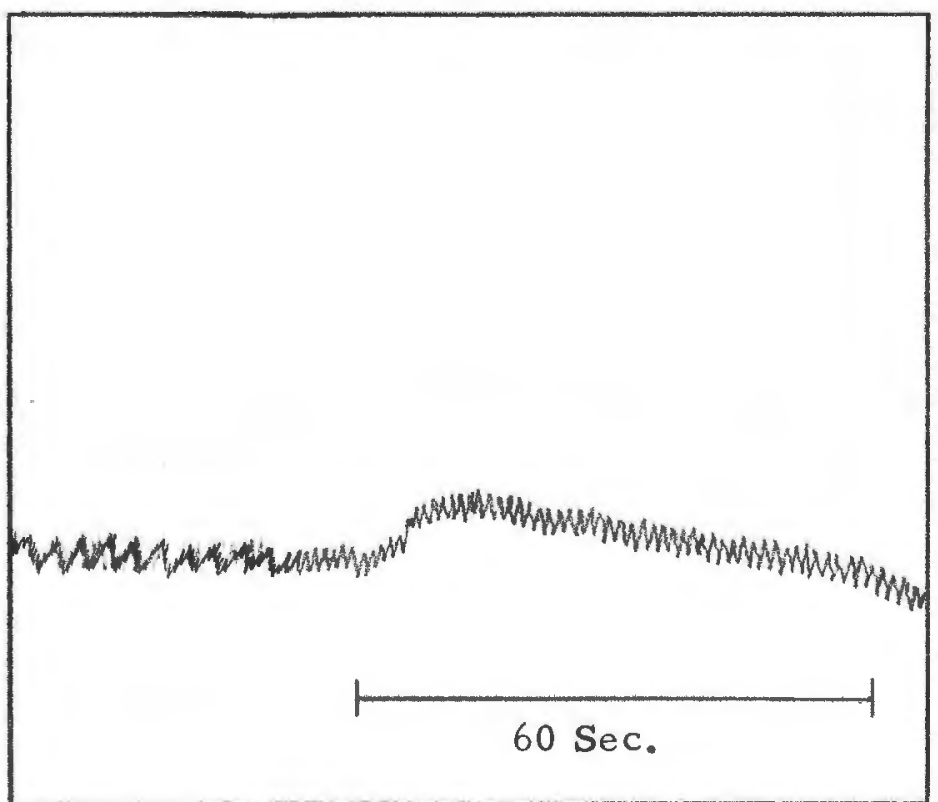

$(\mathrm{TH}-25)$

$\uparrow(4.0 \mathrm{mg} / \mathrm{kg})$

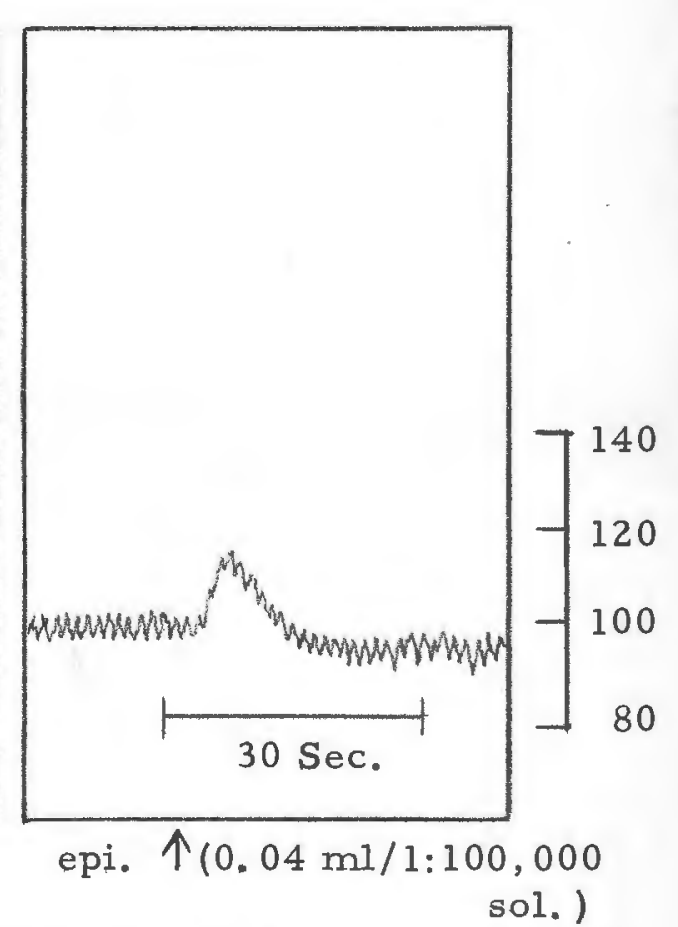
sol.)

Fig. 17 The effect of trans-2-(p-chlorophenyl)-N, N-dimethylcyclohexylamine hydrochloride $(4.0 \mathrm{mg}$. $/ \mathrm{Kg}$.) on the blood pressure of the reserpine pretreated rat following dibenamine (15 mg. $/ \mathrm{Kg}$.). 
response lasting fifty seconds.

(d.) Ten minutes after the slow intravenous injection of dibenamine $(15 \mathrm{mg} / \mathrm{Kg})$, a second injection of trans-2-(p-chlorophenyl)-N, N-dimethylcyclohexylamine hydrochloride ( $\mathrm{TH}-25)$ (4. $0 \mathrm{mg} / \mathrm{Kg}$ ) produced only a 10 per cent increase in blood pressure. The response lasted forty seconds.

(e.) A second injection of epinephrine (0.04 ml of 1:100,000 solution) produced only a 13 per cent increase in blood pressure with a duration of ten seconds. 


\section{DISCUSSION}

\section{A. BLOOD PRESSURE STUDIES}

In a preliminary investigation, Huitric et al. (1959) showed that 2-(-tolyl)-cyclohexanol, given intravenously produced a rapid hypotensive effect in the intact dog. Smookler and DeFeo (1962) reported that cyclohexanol and the cis and trans isomers of its liquid 2-aryl derivatives we re capable of producing an immediate drop in the blood pressure of the intact rat. Although no relationship between the hypotensive response and the molecular spatial configuration could be made, substitution of a tolyl or chlorophenyl moiety in the number two position of the cyclohexanol ring increased the hypotensive activity considerably. The unpublished results of Smith (1963) showed a similar hypotensive response in both the intact rat and cat to the intravenously administered isomers of tolyl and chlorophenyl cyclohexylamine. Once again, correlation between the response and spatial configuration was not evident.

In the present investigation, only the non-ethynyl cyclohexanol derivatives and the cyclohexylamine hydrochloride salts could be tested for hypotensive activity. The solvent system employed for the ethynyI derivatives was found to possess an effect of its own on the blood pressure of the intact rat.

The results obtained with the non-ethynyl cyclohexanol derivatives 
were typical of those previously obtained with other derivatives of cyclohexanol; all produced an immediate drop in blood pressure of short duration (Tables II to IV). The magnitude of the effect appeared to be somewhat proportional to the dose employed, while the duration of the effect did not. On the basis of the calculated ED50 (hypotensive) (Table VIII), little difference in activity exists between trans-2-otolyl-cis-1,4-cyclohexanediol and trans-2-o-tolyl-trans-1, 5-cyclohexanediol. These compounds are the mono-hydroxyl substitution products of trans-2-o-tolylcyclohexanol. The calculated ED 50 (hypotensive) reported by Smookler (1961) for this compound in rats was $0.9 \mathrm{mg} / \mathrm{kg}$. The calculated $E D_{50}$ (hypotensive) for the above compounds was $3.95 \mathrm{mg} / \mathrm{kg}$ and $4.04 \mathrm{mg} / \mathrm{kg}$ respectively. trans-2-oTolyl-cis-4-hydroxy-trans-5-hydroxy-cyclohexanol with an ED 50 of $5.30 \mathrm{mg} / \mathrm{kg}$ represents the di-hydroxyl substitution product of trans2-o-tolylcyclohexanol. It seems likely therefore; that hydroxyl substitution at either the four or the five position of trans-2-o-tolylcyclohexanol causes a 4 fold decrease of hypotensive activity, while hydroxyl substitution at both the four and five position causes an approximate 5 fold decrease of hypotensive activity in the intact rat. This view is supported by Wilson and Gisvold (1956) who state that the activity and toxicity of the parent compound can be expected to decrease upon the introduction of hydroxyl groups into a chemical structure. 
It was observed that these compounds produced periods of labored breathing or dyspnea, particularly with the higher doses used. Artificial respiration in some cases was employed to restore normal function. The duration of respiratory depression appeared to parallel the transient hypotensive response of the blood pressure. Similar periods of dyspnea were observed by Smookler (1961) with the 2-aryl derivatives of cyclohexanol. Likewise, Smith (1963) reported that when death occur red during the blood pressure studies of certain derivatives of cyclohexylamine, respiratory arrest preceded cardiac arrest.

The blood pressure response to the cyclohexylamine hydrochloride salts varied (Tables V to VII). trans-2-(p-Chlorophenyl)-N-methylcyclohexylamine hydrochloride and cis-2-(p-chlorophenyl)-N, N-dimethylcyclohexylamine hydrochloride each produced a depressor response. The duration and magnitude of the response appeared to be somewhat dose related. The hypotensive $\mathrm{ED}_{50}$ calculated for these two compounds was $26.30 \mathrm{mg} / \mathrm{kg}$ and $12.94 \mathrm{mg} / \mathrm{kg}$ respectively (Table VIII). The difference in activity might be due to the cis configuration of the latter compound, the dimethyl substitution of its' amino group or a combination of these. Both compounds affected the respiration in a manner similar to that observed with the non-ethynyl derivatives of cyclohexanol, trans-2-(p-Chlorophenyl)-N, N-dimethylcyclohexylamine hydrochloride on the other hand, produced a pressor response unrelated to 
the three doses investigated (Fig. 3). However, the duration of the response was dose dependent. Respiratory activity following the injection of this compound was observed to increase, in contrast to the respiratory depression which accompanied the injection of the other cyclohexylamine derivatives.

Since the cis-N-methylcyclohexylamine was not available for testing, it would be difficult to say whether the cis configuration alone is responsible for the greater hypatensive activity, or whether such activity is due to both the cis configuration and the $\mathrm{N}, \mathrm{N}$-dimethyl substitution of the compound. In the trans configuration intravenous injection of the secondary amine produced a depressor response, while the tertiary amine similarly administrated produced a pressor response. The cyclohexylamines (both cis and trans) previously tested by Smith (1963) were primary amines and all produced the characteristic drop in rat blood pressure. Thus, it seems likely that the pressor response elicited by trans-2-(p-chlorophenyl)-N, N-dimethylcyclohexylamine hydrochloride is dependent upon both the trans configuration of the compound and the $\mathrm{N}, \mathrm{N}$-dimethyl substitution. An attempt was made to determine the mechanism involved in the pressor response, the discussion of which appears below.

It canbe summarized from the statistical determination of the $E D_{50}$ (hypotensive), that the non-ethynyl derivatives of cyclohexanol were 
2 to 7 times more potent in their ability to lower the blood pressure of the intact rat, than were the derivatives of cyclohexylamine.

In blood pressure experiments, Smookler (1961) and Smookler and DeFeo (1962) reported the production of hematuria by the cyclohexanol compounds investigated. Hematuria was also observed following the intravenous injection of the compounds presently studied. However, gross observation of the plasma of a mixture of heparinized dog blood and each compound failed to reveal hemolysis.

The anesthetic used in this and the previous investigations above, was urethane. Herzog (1925) reported that urethane caused the rupture of red blood cells in the capillaries of the frog. Goodman and Gilman (1955) stated that urethane had a cytotoxic action on the blood. More recently, Bree and Cohen (1965) demonstrated the damaging effects of urethane on blood and blood vessels in rabbits. Among those described, hemolysis was apparent in blood sera samples drawn within two minutes after the induction of anesthesia. In all probability therefore, the hematuria previously reported by Smookler (1961) and Smookler and DeFeo (1962) and presently observed by this author was not caused by the compounds studied, but by the anesthetic employed.

\section{B. ISOLATED HEART STUDIES}

The primary purpose of the investigation was to determine whether or not the compounds possessed cardio-inhibitory properties. Since 
all of the compounds with the exception of trans-2-(p-chlorophenyl)$\mathrm{N}, \mathrm{N}$-dimethylcyclohexylamine hydrochloride produced a rapid and transient fall of the blood pressure in the intact rat, the possibility existed that such an action might be due to direct depression of the myocardium. Indeed, Huitric et al. (1959) observed that 2-(o-tolyl) cyclohexanol produced reversible mechanical cardiac arrest when perfused as a saturated aqueous solution through isolated cat hearts. Moreover, when the isomers of this compound and other aryl substitution products of cyclohexanol were investigated, Smookler and DeFeo (1962) reported that eight of the ten compounds tested on the isolated guinea pig heart were capable of producing cardiac arrest. All of the cyclohexylamine derivatives tested by Smith (1963) produced arrest of the isolated guinea pig heart, as indicated by a depression in the amplitude of contraction of 95 per cent or more.

In the present investigation complete mechanical arrest of the isolated guinea pig heart was produced by each compound except trans2-o-tolyl-cis-4-hydroxy-trans-5-hydroxycyclohexanol. Due to an insufficient amount of this compound only a 10 per cent decrease in the amplitude of cardiac contraction in response to $1.0 \mathrm{mg}$ of the compound was recorded.

Among the other cyclohexanol derivatives tested, 1-ethynyl-cis2-o-tolylcyclohexanol was the most potent while trans-2-o-tolyl- 
cis-1,4-cyclohexanediol was the least potent. (Table XVI). Whereas no difference in hypotensive activity existed between trans-2-o-tolyl-cis1, 4-cyclohexanediol and trans-2-o-tolyl-trans-1, 5-cyclohexanediol, the latter compound was found to be twice as active in producing arrest of the isolated guinea pig heart.

Thus, on the isolated guinea pig heart preparation, if the hydroxyl substituent is moved from the four to the five position of trans-2-0tolylcyclohexanol the cardio-inhibitory activity of the compound is increased by 2 fold. Moreover, when the hydroxyl substituent is omitted and an ethynyl group is substituted at the number one position of the compound, the cardio-inhibitory activity is increased by 3 fold. The activity is increased 5 fold if the latter change in structure is made on the cis isomer.

1-Ethynyl-trans-2-o-tolylcyclohexanol possessed cardiotoxic properties indicated by the irreversible cardiac arrest produced by the minimum effective dose of $3.0 \mathrm{mg}$. Unlike the reversible cardiac arrest produced by the other compounds, the irreversible arrest was characterized by an intense increase in the tone of the myocardium resulting in complete systolic standstill which remained until the experiments were terminated at the end of ninety minutes. On the other hand, 1-ethynyl-cis-2-o tolylcyclohexanol did not show any signs of cardiotoxicity with any of the dosage levels employed. The fact that only one 
of two ethynyl derivatives of cyclohexanol possessed cardio-toxic properties rules out the possibility that the solvent system employed was responsible for this effect. Moreover, control injections showed the solvent to possess a transient positive inotropic effect which occur red concomitant to a transient decrease in the tone of the myocardium. It should be noted, that with the ethynyl compounds the duration of arrest and recovery time were more prolonged than were those of the other cyclohexanol derivatives tested.

In general, a dose-related response to the cyclohexanol derivatives on the isolated guinea pig heart was found to exist with regard to the duration of the cardiac arrest and to the per cent depression in amplitude of contraction produced when no arrest occurred (Tables IX to XII).

The antagonistic effect of various calcium ion concentrations on the negative inotropic response to $1.0 \mathrm{mg}$ of 1 -ethynyl-cis-2-o-tolylcyclohexanol was investigated (Fig. 7). In all cases when injected during cardiac arrest calcium produced a transient positive inotropic response. Since the heart was continuously perfused, the calcium was rapidly washed from the tissue and the condition of cardiac arrest which existed prior to the calcium administration was resumed.

The cyclohexylamine hydrochloride derivatives were the most potent of all the compounds tested on the isolated guinea pig heart (Table XVI). From the table, little difference in cardio-inhibitory 
activity exists between the trans and cis isomers of 2-(p-chlorophenyl)$\mathrm{N}, \mathrm{N}$-dimethylcyclohexylamine hydrochloride. However, both of these compounds were approximately 25 per cent more active than was trans2-(p-chlorophenyl)-N-methylcyclohexylamine hydrochloride based on the calculated ED $_{95}$ (cardio-inhibitory). The negative inotropic response occurring in the absence of arrest was approximately the same for all three compounds; however, the period of arrest and recovery time were both of longer duration following the administration of cis-2(p-chlorophenyl)-N, N-dimethylcyclohexylamine hydrochloride (Tables XIII to XV). Smookler and DeFeo (1962) reported that the chlorophenyl substituted derivatives of cyclohexanol possessed cardio-toxic properties as evidence by the failure of most of the hearts studied to recover from the effects of these compounds. On this basis, none of the chlorophenyl substituted derivatives of cyclohexylamine presently investigated exhibited cardiotoxicity.

It will be recalled that trans-2-(p-chlorophenyl)-N, N-dimethylcyclohexylamine hydrochloride produced a response on the blood pressure of the intact rat completely opposite to that produced by its "isomer. Nevertheless, the two isomers were equally potent and the most active compounds in producing arrest of the isolated guinea pig heart.

The effects of the cyclohexylamine hydrochloride salts on the rate 
of coronary flow were studied by recording the time required to collect $1.0 \mathrm{ml}$. of effluent perfusate. The trans isomers of the tertiary amine and the secondary amine showed a time increase over control values of 100 per cent and of 88 per cent respectively. Thus, these compounds also increase coronary vascular resistance in conjunction with their negative inotropic effects.

On the basis of the calculated ED95 (cardio-inhibitory) of the cyclohexanol and cyclohexylamine derivatives (Table XVI), the cyclohexylamine derivatives were up to 8 times more potent than were the cyclohexanol derivatives. Only a slight difference in activity existed among the three cyclohexylamines tested, while as much as a 5 fold variation in activity existed between the cyclohexanol derivatives. Both the cationic amino group and the chloro substituent on the aromatic ring may account for the greater activity of the cyclohexylamine hydrochloride salts.

The ethynyl derivatives were the most active of the cyclohexanol compounds. However, the minimum effective dose of the trans isomer was also the cardio-toxic dose. From the effects produced by the other cyclohexanol derivatives on the isolated guinea pig heart it is apparent that the presence of additional hydroxyl substituents on the cyclohexanol ring (specifically at the four and/or five positions) is responsible for the decrease in activity associated with these compounds. 


\section{ISOLATED ATRIAL STUDIES}

Preliminary mechanism and site of action studies were performed on spontaneously beating isolated rat atria. Smookler and DeFeo (1962) reported that trans-2-(o-tolyl) cyclohexanol was immediately effective in reducing the contraction amplitude of isolated rabbit atria without affecting the rate. The investigators further observed that the calcium ion antagonized this effect by restoring the amplitude to a normal level.

In the present study, trans-2-o-tolyl-trans-1,5-cyclohexanediol similarly depressed the contraction amplitude of isolated rat atria without affecting the rate. Likewise, the amplitude was quickly restored to a control level by the administration of calcium (Fig. 12). Antagonism between the compound and the calcium ion was also demonstrated when both were administered simultaneously. The resulting increase in amplitude was only two thirds of that produced when calcium was added alone. In addition, the rate of the increase in amplitude, and the duration of the peak effect were also reduced.

cis-2-(p-Chlo rophenyl)-N, N-dimethylcyclohexylamine hydrochloride produced both negative inotropic and chronotropic effects on the isolated rat atria. The decrease in contraction amplitude was preceded in all instances by a positive inotropic response. The duration of this response was shorter when the dose of the compound was increased. In the unpublished work by Smith (1963) the cyclohexylamines investigated 
reportedly increased the contraction amplitude of rat atria while decreasing the rate. The negative inotropic effect was not observed, since the investigator allowed only a three minute period of tissue exposure before washing the preparation.

In the present study, the negative inotropic effect did not appear until after three minutes, although the negative chronotropic effect progressed throughout the entire exposure time. Calcium was able to restore the amplitude to control level but unable to restore the rate (Fig. 13).

Since the compound and the calcium salts each produced a positive inotropic response within ninety seconds, it seemed likely, that if both were administered together, a summation of the responses would occur within this time. This was not demonstrated and the delayed positive inotropic response which did occur was of the same magnitude as that produced by the compound.alone. Moreover, after a slight increase, the rate of contraction diminished in a manner similar to that observed when the compound was given alone.

Thus, on the isolated rat atria and with the concentrations employed, the cyclohexanol derivative affected the force of contraction while both the force and rate of contraction were affected by the cyclohexylamine derivative. Calcium antagonized the negative inotropic effects of the compounds when administered after these had occurred. The 
onset of the inotropic effect of each compound was delayed by the calcium if both were given simultaneously. However, the cation was unable to overcome the negative chronotropic response to the cyclohexylamine derivative.

The results obtained with the cyclohexanol derivative support the observations of Smookler and DeFeo (1962). The negative inotropic and chronotropic effects produced by the cyclohexylamine derivative indicate a possible quinidine-like action on the myocardium. Conn and Luchi (1964) point out that the most critical reactive site in the quinidine molecule is the tertiary nitrogen. The investigators also speculate that quinidine chelation of calcium may underlie its' depressant effects on myocardial contractility.

In view of the recent emphasis on calcium as the critical mediator of excitation-contraction coupling, and the antagonism demonstrated between calcium and the inotropic action of the compounds presently investigated, it seems probable that chelation of calcium may be of significance in the action of these compounds.

D. PRELIMINARY INVESTIGATION OF THE PRESSOR RESPONSE TO (TH-25).

Despite the pressor activity of trans-2(p-chlorophenyl)-N,Ndimethylcyclohexylamine hydrochloride, the compound was the most potent in arresting the isolated guinea pig heart. In view of these 
findings, additional blood pressure experiments were carried out in an effort to understand more completely the mechanism involved in the pressor response.

The first of these experiments failed to indicate that baroreceptor activity might have induced reflex vasoconstriction. Hexamethonium prevented the pressor response to carotid occlusion but did not affect the responses to epinephrine or the compound (Figs. 14 and 15). The second experiment demonstrated that the depletion of catecholamine stores by reserpine did not alter the compounds pressor activity. The only significant change in the pressor response occurred when the compound was injected after the administration of dibenamine (Figs. 16 and 17). Due to an insufficient supply of the compound, the mechanism involved in the pressor response was pursued no further.

However, from these results and those previously obtained from the isolated heart and blood pressure experiments, it is indicated that the pressor response to the intravenous injection of trans-2-(p-chlorophenyl)-N, N-dimethylcyclohexylamine hydrochloride stems from the compounds ability to produce peripheral vasoconstriction. The interpretation is supported somewhat, by Marsh (1948) who reported that certain cyclohexylalkylamines possessed pressor activity. Moreover, Fellows et al. (1950) showed the increase in blood pressure produced by the cyclohexylalkylamines studied was due to increased peripheral 
vasoconstrictor activity.

\section{E. CORRELATIONS}

Molecular structure and spatial configuration influenced the relative cardiovascular activity of the compounds studied. An inverse relationship existed between a compound's ability to arrest the isolated guinea pig heart, and its' ability to lower the blood pressure of the intact rat. The cyclohexylamine derivatives which were the most active in the former group of experiments were the least active in the latter group; in one instance a pressor response occurred. A decrease in coronary flow accompanied the cardioplegic activity of the cyclohexylamine compounds. Whether or not this was a direct effect of the compound, on the coronary vasculature, was not determined. On the basis of recovery from induced cardiac arrest, only one compound was cardiotoxic.

Calcium was able to momentarily restore contraction of the heart arrested by one of the cyclohexanol derivatives; and in the isolated atria, calcium antagonized the negative inotropic effects of representatives from both series of compounds. The cyclohexylamine compound also possessed a negative chronotropic affect on the isolated atria, which was unaltered by the calcium administration.

In view of the isolated heart and atrial experiments, cyclohexanol cardioplegia appears to result from an alteration in the electrolyte 
balance thereby modifying the contraction of the myocardium. On the other hand, the cyclohexylamine cardioplegia appears to result from either altered impulse formation, or suppressed impulse conduction, in addition to the decrease in contraction of the myocardium mentioned above. Under these conditions, it might also be expected that eventual atrio-ventricular dissociation could bring about the observed asystole. To definitely understand the mechanism of the observed cardioplegia, electrocardiograms and transmembrane potentials should be recorded in conjunction with the isolated tissue experiments.

Although beyond the scope of the investigation, preliminary studies indicated that the pressor response to one of the cyclohexylamine derivatives resulted from the compounds direct action on the peripheral vasculature. Further experimental evidence is needed to confirm this. 


\section{SUMMARY AND CONCLUSIONS}

A. A series of synthetic chemical compounds were pharmacologically screened for cardioplegic and hypotensive activity with the purpose of relating such activity to the structural arrangement of the compounds and to attempt to determine the mechanism through which the compounds acted.

B. As a group, the non-ethynyl cyclohexanol derivatives were 2 to 7 times more potent than were the derivatives of cyclohexylamine in producing a hypotensive response in the intact rat. trans-2-o-Tolylcis-1,4-cyclohexane diol and trans-2-o-tolyl-trans-1, 5-cyclohexanediol were equally effective and the most active, while the trans isomer of the tertiary cyclohexylamine was the least active and the only compound that produced a pressor response.

C. The cyclohexylamine derivatives were up to 8 times more potent in arresting the isolated guinea pig heart, than were the derivatives of cyclohexanol. The cis and trans isomers of the tertiary cyclohexylamine were equally effective and the most active; while trans-2-otolyl-cis-1,4-cyclohexanediol possessed the least amount of cardio-. inhibitory activity among those compounds studied.

D. An increase in the number of hydroxy substituents on the cyclohexanol ring was accompanied by a decrease in both hypotensive and cardio-inhibitory activity. 
E. The minimum effective dose of 1 - ethynyl-trans-2-o-tolyleyclohexanol in producing cardiac arrest was also the cardio-toxic dose; while the cis isomer showed the greatest cardio-inhibitory activity among the cyclohexanol derivatives studied.

F. Spatial configuration was also significant in the blood pressure activity of the tertiary cyclohexylamines. The cis isomer produced a depressor response in contrast to the pressor response elicited by the trans isomer.

G. In the isolated atrial preparation, calcium antagonized the negative inotropic effects of trans-2-o-tolyl-trans-1,5-cyclohexanediol and cis2-(p-chlorophenyl)-N, N-dimethylcyclohexylamine hydrochloride. Moreover, calcium momentarily restored contraction of the heart arrested by 1-ethynyl-cis-2-o-tolylcyclohexanol.

H. In addition to its' negative inotropic effect on the isolated atria, cis - 2-(p-chlorophenyl)-N, N-dimethylcyclohexylamine hydrochloride also produced a negative chronotropic response which was unaffected by the administration of calcium.

I. Decreased contraction of the myocardium appears to be responsible for the cardioplegia produced by the cyclohexanol compounds, since the pacemaker activity of the isolated atrial preparation is not affected. $\mathrm{J}$. In addition to a decreased contraction of the myocardium, alteration of impulse formation or suppression of impulse conduction appear to be 
responsible for the cardioplegia produced by the cyclohexylamine derivatives.

K. Preliminary studies of the pressor response to trans-2-(p-chlorophenyl)-N, N-dimethylcyclohexylamine hydrochloride indicate that the compound is capable of producing peripheral vasoconstriction.

L. It was suggested that the appearance of hematuria at the conclusion of the blood pressure experiments occurred as a result of the blood damaging and cytotoxic properties of the anesthetic agent, and was not an effect of the compounds investigated.

M. The implications of these findings, and the relationship between chemical structure and activity are discussed. 


\section{REFERENCES}

Baer, S. B., Montgomery, V., Blair, E. and Swan, H.: The relation of coronary blood flow to prevention of ventricular fibrillation in the cold canine heart. Surg. Forum 6: 200, 1956.

Baker, J. B. E. and Dreyer, B.: Cardiac arrest by potassium citrate. J. Physiol. 131: 25P, 1956.

Bentall, H. H. and Melrose, D. G.: Elective cardiac arrest: lactic acid production in the arrested heart. J. Physiol. 135: 38P, 1957.

Berne, R. M. , Jones, R. D. and Cross, F. S.: Evaluation of selective cardiac hypothermia and potassium arrest of the heart. J. Thoracic and Cardiovascular Surg. 47: 283, 1964.

Bhonslay, S. B., Deterling, R. A. Jr., Wallace, H. W. and Rheinlander, H. F.: Elective cardiac arrest. J. Cardiovascular Surg. $\underline{\text { : }}$ $168,1961$.

Bjork, V. O.: Brain perfusion in dogs with artifically oxygenated blood. Acta. Chir. Scandinav. 96: supp. 137, 1948.

Bjork, V. O. and Fors, B.: Induced cardiac arrest. J. Thoracic and Cardiovascular Surg. 41: 387, 1961.

Bree, M. M. and Cohen, B. J.: Effects of urethane anesthesia on blood and blood vessels in rabbits. Lab. Animal Care 15: 254, 1965.

Brewer, L. A. III, Coggin, C. J., Wareham, E. E. and Henshaw, D. B. : Elective cardiac arrest in open heart surgery with cardiopulmonary by-pass, Bull. Soc. Int. Chir. 21: 522, 1963.

Burdette, W. J. and Al-Shamma, A.: Changes in high energy phosphates during cardiac arrest. Arch. Surg. 85: 4, 1962.

Burn, J. H. and Vane, J. R.: The relation between the motor and inhibitor actions of acetylcholine. J. Physiol. 108: 104, 1949.

Chenoweth, M. B. and Koelle, E. S.: An isolated heart perfusion system adapted to the determination of non gaseous metabolites. J. Lab. Clin. Med. 31: 600, 1946.

Clark, L. C. Jr., Berg Champ Lyons, F., Kaplan, S. and Edwards, W. S.: Continuous perfusion of the arrested heart with arterialized hypocalcemic blood. Surg. Forum 10: 518, 1959. 
Conn, H. L. Jr. and Luchi, R. J.: Some cellular and metatolic considerations relating to the action of quinidine as a prototype antiarrhythmic agent. Am. J. Med. 37: 685, 1964.

Cooper, T., Willman, V. L., Zafiracopoulos, P. and Handon, C. R. : Myocardial function after elective cardiac arrest during hypothermia. Surg. Gynec. Obstet. 109: 423, 1959.

Cooper, T., Willman, V. L., Zafiracopoulos, P. and Handon, C. R.: Use of cardiotonic agent (mephentermine) in myocardial depression due to potassium. Arch. Surg. 79: 734, 1959a.

Cooper, T., Willman, V. L., Zafiracopoulos, P. and Handon, C. R, : Effect of prophylactic digitalization on myocardial function after elective cardiac arrest. Ann. Surg. 151: 17, 1960.

Dodrill, F. D. and Takagi, S.: The use of anaerobic energy in elective cardiac arrest. Surgery 47: $314,1960$.

Effler, D. B., Groves, L. K., Sones, F. M. Jr. and Kolff, W. J.: Elective cardiac arrest in open heart surgery. Cleveland Clin. Quart. 23: $105,1956$.

Effler, D. B., Groves, L. K., Sones, F. M. Mr. and Kolff, W. J.: Elective cardiac arrest - an adjunct to open heart surgery. $\mathrm{J}$. Thoracic Surg. 34: 500, 1957.

Fellows, E. J., Macko, E. and Mc Lean, R. A.: Observations on several cyclohexyl - and phenyl-alkylamines. J. Pharmacol. 100: $267,1950$.

Gibbon, J. H. Jr.: The application of a mechanical heart-lung apparatus to cardiac surgery. Minnesota Med. 37: 171, 1954.

Goodman, L. and Gilman, A.: Pharmacological Basis of The rapeutics, p. 1427, Macmillan, New York, 1955.

Gott, V. L., Bartlett, M., Johnson, J. A. , Long, D. M. and Lillihei, C. W.: High energy phosphate levels in the human heart during potas sium citrate arrest and selective hypothermic arrest.: Surg. Fórum 10: $544,1959 . \therefore$

Gott, V. L., Dutton, R. C. and Young, W. P.: Myocardial rigor mortis as an indicator of cardiac metabolic function. Surg. Forum 13: $172,1962$. 
Halpern, B. N., Du Bouchet, N. and Neveu, T.: Effect of hexamethonium on the presso-receptive reflexes of the carotid sinus. C. $R$. Soc. Biol. Paris, 148: 1172, 1954.

Headrick, J. R., Strayhorn, W. D., Munoz, A. J. and Adams, J. E.: A method of safely prolonging induced cardioplegia. Surg. Forum 10: $509,1959$.

Helmsworth, J. A., Shabetai, R. W. and Margolian, J.: An investigation of cardiac arrest produced by injection of potassium citrate into the coronary circulation. J. Thoracic Surg. 36: 214, 1958.

Herzog, F.: Uber beziehungen zwischen dilatation duchlassigheit and phagocytose an den capillaren der froschzunge. Virchows Archives 256: $1,1925$.

Hooker, D. R.: On recovery of heart in electric shock. Am. J. Physiol. 91: 305, 1929.

Huitric, A. C., West, T. C., Durbin, R. A, and Bryan, G. H.: 2-(o-Tolyl)-cyclohexanol: A possible cardioplegic agent. J. Amer. Pharm. Ass., Sci. Ed. 48: 132, 1959.

Kaplan, S., Clark, L. C., Mathews, E. C., Edwards, F。 K., Schwab, L. and Helmsworth, J. A.: A comparison of the results of total body perfusion in dogs during potassium citrate cardiac arrest, sinus rhythm, and induced ventricular fibrillation. Surgery 43: 14, 1958.

Kaplan, A. and Fisher, B.: Study of cardioplegic action of potassium ion during normothermia and hypothermia. Ann. Surg. 150: 833, 1959.

Kaplan, A. and Fisher, B.: Influence of different carriers upon the cardioplegic activity of potassium ion. Ann. Surg. 156: 869, 1962 .

Kenyon, N. M., Litivak, R. S., Beck, H. J., Slonine, R. J., Spears, H. C. and Shibota, Y.: Preliminary observations in isolated hypothermic cardiac asystole. Surg. Forum 10: 567, 1959.

Kolff, W. J., Effler, D. B., Groves, L. K., Peere Boom, G. , Aoyama, S. and Sones, F. M. Jr.: Elective cardiac arrest by the melrose technique. Cleveland Clin. Quart. 23: 98, 1956.

Kolff, W. J., Effler, D. B., Groves, L. K. and Moraca, P. P.: Elective cardiac arrest with potassium citrate during open heart operations. J. Amer. Med. Ass. 164: 1953, 1957. 
Kusinoki, T., Cheng, H. C., Mc Guire, H. H. Jr. and Bosher, L. H. Jr.: Myocardial dysfunction after cardioplegia. J. Thoracic and Cardiovascular Surg. 40: 813, 1960 。

Lam, C. R., Gahagan, $T_{\text {。 }}$ and Lepore, $A_{\text {. }}$ : Induced cardiac arrest for intracardiac surgical procedures. J. Thoracic Surg. 30: 620, 1955.

Lam, C. R., Gahagan, T., Sergeant, C. and Green, E.: Clinical experiences with induced cardiac arrest during intracardiac

surgical procedures. Ann. Surg. 146: 439, 1957.

Lam, C. R., Gahagan, T., Sergeant, C. and Green, E.: Experiences in the use of cardioplegia (induced cardiac arrest) in the repair of interventricular septal defects. J. Thoracic Surg. 34: 509, 1957a.

Lam, C. R., Gahagan, T., Mota, C. and Green, E.: In duced cardiac arrest (cardioplegia) in open heart surgical procedures. Surgery 43: $7,1958$.

Lewis, F. J. and Taufic, M. : Closure of atrial septal defects with aid of hypothermia. Surgery 33: 52, 1953.

Marsh, D. F.: The comparative pharmacology of the cyclohexylalkylamines. J. Pharmacol. 93: 338, 1948.

Mc Farland, J. A., Thomas, L. B., Gilbert, J. W. and Morrow, A. G.: Myocardial necrosis following elective cardiac arrest induced with potassium citrate. J. Thoracic Cardiovascular Surg. 40: 200, 1960.

Mc Kain, J. M., Poepsel, H. F., Badame, J. M. and Carnazzo, A. J.: Control of cardiac activity by ischemia and hypothermia. Arch, Surg. 82: $511,1961$.

Melrose, D. G., Dreyer, B., Bentall, H. H. and Baker, J. B. E.: Elective cardiac arrest. Lancet 269: 21, 1955.

Merritt, D. H., Sealy, W. C., Young, W. G. Jr. and Harris, J. S.: Evaluation of cardioplegic drugs for surgery using isolated perfused cat heart. Arch. Surg. 76: 365, 1958.

Miller, D. R., Rasmussen, P., Khonsky, B., Cossman, F. P. and Allbritten, F. F. Jr.: Elective cardiac arrest - its' effect on myocardial structure and function. Ann. Surg. 154: 751, 1961. 
Miller, D. R., Rasmussen, P. and Khonsky, B.: Reversibility of Morphological changes following elective cardiac arrest. Ann. Surg. 159: 208, 1964.

Milnes, R. F., vander Wonde, R., Sloan, H. and Morris, J. D.: Extended asystole. Arch. Surg. 77: 131, 1958.

Moulder, P. V., Thompson, R. G., Smith, C. A., Siegel, B. L. and Adams, W. E.: Cardiac surgery with hypothermia and acetyl choline arrest. J. Thoracic Surg. 32: 360, 1956.

Mouritzen, C. and Albrechtsen, O. K. : Controlled arrest of isolated perfused rabbit hearts, I. Dan. Med. Bull. 7: 134, 1960.

Mouritzen, C. and Albrechtsen, O. K.: Controlled arrest of isolated rabbit hearts, II. Dan. Med. Bull. 8: 43, 1961.

Nelson, R. M., Mason, J., Maxwell, G., Nelson, J., Peters, J. and Hardy, R.: In : Extracorporeal Circulation. (J. G. Allen, ed.), pp. 487-490. Thomas, Springfield, 1958.

Parker, E. F., Stilwell, J. R., Bradham, G. B., Tenney, J. M. and Darby, T. D.: The effect of acetylcholine arrest on ventricular contractile force with cardio-pulmonary by-pass. J. Thoracic Cardiovascular Surg. 41:,770, 1961.

Redo, S. F.: An evaluation of various cardioplegic methods utilizing isolated perfused guinea pig hearts. Surg. Gynec. Obst. 108: 211, 1959.

Redo, S. F.: Prolonged Cardioplegia. Arch. Surg. 85: 483, 1962.

Redo, S. F. and Porter, B. Y.: The role of the lack of oxygen in irreversible cardiac arrest. Surg. Gynec. Obst. 109: 431, 1959.

Ringer, S.: Concerning the influence exerted by each of the constituents of the blood on the contraction of the ventricle. J. Physiol, 3: 380,1882 .

Ringer, S.: A further contribution regarding the influence of the different constituents of the blood on the contraction of the heart. $J$. Physiol. 4: 29, 1883. 
Sealy, W. C., Young, W. G. Jr., Brown, I. W. Jr., Lesage, A., Callaway, H. H. Jr., Harris, J. S. and Merritt, D. H.: Potassium, magnesium and neostigmine for controlled cardioplegia: studies on the dog using extracorporeal circulation and hypothermia. Arch. Surg. 77: $33,1958$.

Senning, A.: Ventricular fibrillation during extracorporeal circulation used as a method to prevent air-embolism and to facilitate intracardiac operations. Acta. Chir. Scandinav. 100: supp. 171, 1952.

Sergeant, C. K., Gagahan, T. and Lam, C. R.: Further studies in induced cardiac arrest using the agent acetylcholine. Surg. Forum 7: $254,1956$.

Smith, J. C. Jr.: Comparative cardiovascular effects of substituted cyclohexane derivatives. M. S. Thesis, University of Rhode Island, 1963.

Smookler, H. H.: The comparative cardio-inhibitory effects of substituted cyclohexanols. M. S. thesis, University of Rhode Island, 1961 .

Smookler, H. H. and DeFeo, J. J.: Comparative cardio-inhibitory effects of substituted cyclohexanols. J. Pharm. Sci. 51: 736, 1962.

Stephenson, H. E. Jr.: Cardiac arrest and resuscitation. Mosby, St. Louis, 1964.

Weirich, W. L., Jones, R. W. and Burke, M. F.: The effect of elective cardiac arrest induced by potassium citrate and acetylcholine on ventricular function. Surg. Forum 10: 528, 1959.

Willman, V. L., Cooper, T., Zafiracopoulos, P. and Handon, C. R.: Depression of ventricular function following elective cardiac arrest with potassium citrate. Surgery 46: 792, 1959.

Willman, V. L., Cooper, T., Zafiracopoulos, P. and Handon, C. R.: Measures to limit myocardial depression as sociated with elective cardiac arrest. Surg. Forum 10: 514, 1959a.

Wilson, C. O. and Gisvold, O.: Textbook of Organic Medicinal and Pharmaceutical Chemistry, p. 89, Lippincott, Philadelphia, 1956. 
Yashar, J. J., DeFeo, J., DeFanti, D. and Kiven, N.: Experimental use of cardioplegic agents in open heart surgery. R. I. Med. J. 43: $569,1960$. 


\section{ACKNOWLEDGEMENTS}

The author is sincerely grateful for the guidance given throughout this investigation by Dr. John $J$. DeFeo and the members of the graduate committee.

The author gratefully acknowledges the encouragement and confidence of his wife, Marie.

The author wishes to express his gratitude for the inspiration and continued understanding of his parents, Mr. and Mrs. Herman A. Kosegarten.

The author acknowledges that a Rhode Island Heart Association grant helped support this investigation. 